\title{
Three stories on Eph kinase inhibitors: from in silico discovery to in vivo validation
}

\author{
Andrea Unzue, ${ }^{a}$ Karine Lafleur, ${ }^{\text {a, } 1}$ Hongtao Zhao,, 2 Ting Zhou, ${ }^{\text {b, } 3}$ Jing Dong, ${ }^{\text {b, } 4}$ Peter \\ Kolb, ${ }^{\text {b, } 5}$ Johanna Liebl, ${ }^{\mathrm{c}}$ Stefan Zahler, ${ }^{\mathrm{c}}$ Amedeo Caflisch,, ${ }^{*, \mathrm{~b}}$ and Cristina Nevado*,a \\ aDepartment of Chemistry and ${ }^{b}$ Department of Biochemistry, University of Zürich, \\ Winterthurerstrasse 190, CH-8057 Zürich, Switzerland \\ 'Department of Pharmacy, Pharmaceutical Biology, Ludwig Maximilians University Münich, \\ Butenandtstrasse 5-13, 81377 Münich, Germany \\ ${ }^{1}$ Present address: DSM, Switzerland \\ ${ }^{2}$ Present address: Medivir AB, Stockholm, Sweden \\ ${ }^{3}$ Present address: ESBAtech, Novartis, Wagistrasse 12, 8952 Schlieren, Switzerland \\ ${ }^{4}$ Present address: Astex Pharmaceuticals, 436 Cambridge Science Park Rd, Cambridge CB4 \\ OQA, United Kingdom \\ ${ }^{5}$ Present address: Department of Pharmaceutical Chemistry, Philipps-University Marburg, \\ Marbacher Weg 6, 35032 Marburg, Germany
}

Several selective and potent EphB4 inhibitors have been discovered, optimized and biophysically characterized by our groups over the past years. On the outset of these discoveries high throughput docking techniques were applied. Herein, we review the optimization campaigns started from three of these hits (Xan-A1, Pyr-A1 and Qui-A1) with emphasis on their in depth in vitro and in vivo characterization, together with previously unpublished angiogenesis and fluorescence based assays.

Keywords: drug discovery, EphB4, in silico, kinase, potency, selectivity

\section{Introduction}

Kinases are one of the largest families of enzymes. The 518 protein kinases encoded in the human genome ${ }^{1}$ catalyze the transfer of the $\mathrm{Y}$ phosphate from ATP to the hydroxyl group of serine, threonine or tyrosine mainly in signaling proteins. Thus protein kinases regulate key biological processes including cell differentiation, proliferation, and motility.

Receptor tyrosine kinases (RTK) are transmembrane proteins that undergo a conformational change upon the binding of signaling molecules to the extracellular domain ( $\mathrm{N}$-terminal domain). The conformational change triggers the autophosphorylation of tyrosine residues in the RTK located in the intracellular domain. Subsequently, the activated RTK are able to phosphorylate a variety of cytoplasmic signaling proteins, which transmit a cellular response that induces the transcription of specific genes among many other processes. Thus, the activity of protein kinases has been linked to a wide variety of therapeutic areas 
such as oncology, ${ }^{2}$ neurology ${ }^{3}{ }^{\text {immunology }},{ }^{4}$ cardiology ${ }^{5}$ and infectious diseases. ${ }^{6}$ Among these, cancer has been notably addressed, and as certain protein kinases are overexpressed in many cancer cells, kinase inhibition has been sought for the development of targeted anti-cancer agents.

Eph (erythropoietin-producing human hepatocellular carcinoma) RTKs are the largest RTK family. ${ }^{7}$ They are divided into two families, EphA and EphB, which preferentially bind to ephrin-A or ephrin-B ligands respectively. ${ }^{8}$ The Eph-ephrin system is characterized by its bidirectional signaling, as it induces a downstream signalling into the Eph containing cell and an upstream signaling into the ephrin containing cell, ${ }^{9}$ which enables cell-cell communication, cell migration, cell repulsion and adhesion to the extracellular matrix among other processes. As a consequence, Eph-ephrin interactions modulate several mechanisms of the nervous system, where they are highly expressed, such as axon guidance during neural development, development of the visual system and vascular development during embryogenesis. ${ }^{10}$

Eph receptors and ephrins are also involved in the growth, maturation and remodeling of blood vessels. The EphB4-ephrinB2 interaction in particular plays a prominent role in the cardiovascular development and it regulates vascularization of malignant tumors. In fact, EphB4 overexpression has been linked to several tumor types such as breast, ${ }^{11}$ prostate, ${ }^{12}$ colon, ${ }^{13}$ uterus, ${ }^{14}$ melanoma ${ }^{15}$ and ovarian cancer $^{16}$ among others. ${ }^{17}$ EphB4 has been associated to angiogenesis, tumor growth and metastasis, making it a valuable target for therapeutic applications. However, the role of EphB4 in cancer remains a matter of debate, since Eph-ephrin interactions have been shown to either promote or inhibit tumor growth. ${ }^{11-12 \text {, }}$ $18-21$

Several anti-cancer strategies that address the EphB4-ephrinB2 interaction have been developed. Soluble fusion proteins of the extracellular domain of EphB4 that antagonize EphB4-ephrinB2 interaction could inhibit tumor growth and angiogenesis in tumor xenograft models, confirming the importance of EphB4 in oncology. ${ }^{22-23}$ Moreover, monoclonal antibodies and peptides that block EphB4-ephrinB2 interaction have also been described. ${ }^{24-27}$ Surprisingly, only a few potent inhibitors of the kinase domain of Eph receptors have been reported (I-IX, Figure 1). ${ }^{28-38}$ Different binding modes have been disclosed for these molecules: ${ }^{39}$ type I (such as $\mathrm{I}^{28}$ and $\mathrm{II}^{29}$ ) are ATP competitors that recognize the activated state of the kinase); type II (e.g V and VII) ${ }^{34}$ interact with an inactive conformation of the kinase and generally offer better selectivity profiles, and type $I_{1 / 2}$ inhibitors (e.g. $\mathrm{II}^{31}$ ) that bind to the kinase in the active DFG-in conformation, but extend their interactions to the hydrophobic back pocket establishing the characteristic hydrogen bonds present in type II inhibitors. ${ }^{39}$

Efficacy data with the selective EphB4 inhibitor NVP-BHG712 (VII) have been reported, showing inhibition of VEGF driven angiogenesis in vivo. ${ }^{36}$ Several of the FDA approved kinase inhibitors, such as dasatinib, ${ }^{40}$ bosutinib, vandetanib, crizotinib and nilotinib, ${ }^{41-43}$ as well as other multi-kinase inhibitors ${ }^{44-48}$ are also able to inhibit EphB4 among other kinases. 

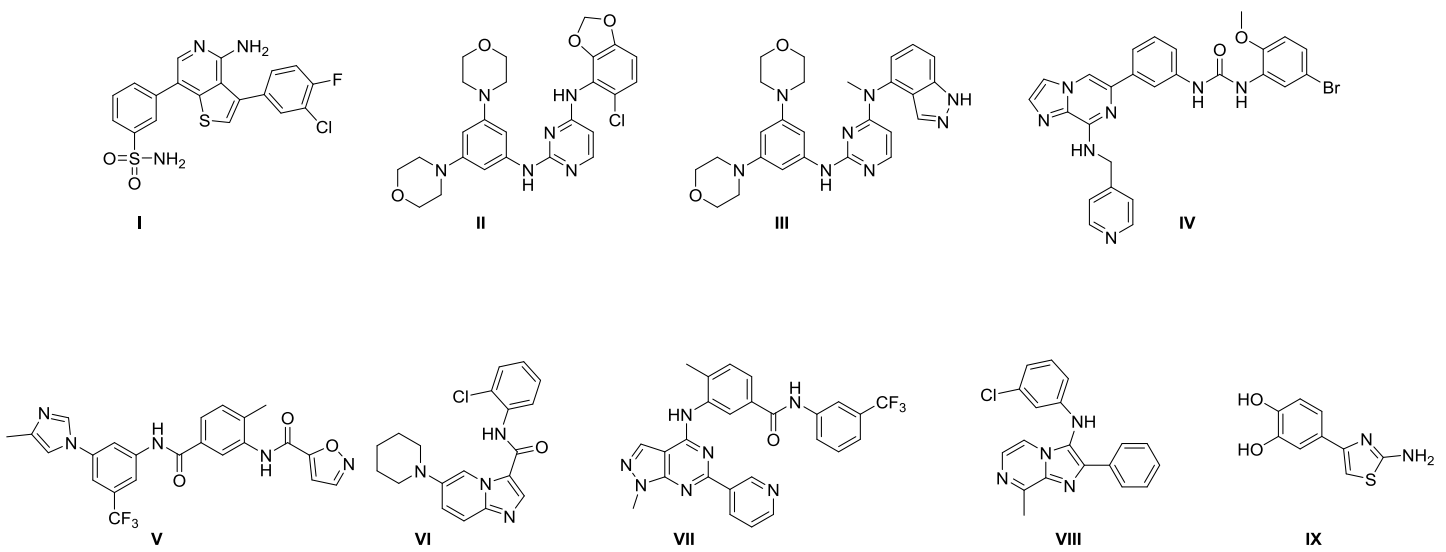

Figure 1. Previously reported nanomolar inhibitors of Eph kinases. ${ }^{28-38}$

Our groups at the University of Zurich have contributed to the discovery, optimization and characterization of several selective and potent EphB4 inhibitors. On the outset of these discoveries high throughput docking techniques were applied. Specifically, we have developed an efficient computational method called ALTA (Anchor-based Library Tailoring) that generates a focused library and prioritizes molecular fragments according to their binding energy. ${ }^{49}$ As a first step, millions of commercially available molecules are automatically decomposed into predominantly rigid fragments which are docked in the binding site of the protein. Fragments with the most favorable binding free energy (also called anchors) are used to retrieve the molecules which they originated from. These molecules are then submitted to flexible ligand docking. Finally, compounds are ranked according to their interaction energy taking into account desolvation effects, and visual inspection from the top ranked compounds starts. This in silico fragment-based approach has resulted in the identification of xanthines Xan-A1, Xan-A2 and Xan-A3 ${ }^{49}$ and pyrimidoisoquinolinone Pyr-A1 ${ }^{50}$ as low micromolar EphB4 inhibitors (Figure 2).

We have also successfully applied semi-empirical quantum mechanical (QM) calculations for rapidly screening compound poses generated by high throughput docking. ${ }^{51}$ A total of 2.7 million of commercially available compounds were docked in the ATP binding site of EphB4 generating ca. 100 million poses. Their binding energy was estimated by calculating the formation enthalpy in the presence of small molecules (called QM probes) emulating functional groups in the hinge region and at the entrance of the binding pocket. This study resulted in the discovery of a low micromolar EphB4 inhibitor, 2-formamido-4phenylthiophene-3-carboxamide Thio-A1, whose binding mode was confirmed by X-ray crystallography of a close derivative in complex with EphA3 (PDB code 4TWO) ${ }^{52}$

Further high throughput docking studies were performed using an inactivated DFG-out conformation of the EphA3 kinase obtained by explicit solvent molecular dynamics (MD) simulations. ${ }^{53}$ This campaign resulted in the discovery of a new scaffold, 5-(piperazine-1yl)isoquinoline and in particular compound Pip-C1 (Figure 2) which is a novel type II inhibitor that presents low micromolar affinity for EphA3 and unphosphorylated Abelson tyrosine kinase $(\mathrm{Abl} 1) .^{53}$

In another high throughput docking campaign, an evaluation of the hydrogen bonding penalty upon ligand binding was integrated to the binding energy calculation. ${ }^{54}$ This study resulted in the discovery of three novel Eph inhibitor scaffolds: quinoxalines (Qui-A1 and 
Qui-A2, with nanomolar affinities for EphB4) and the micromolar inhibitors triazolo[4,3a]quinazoline (Tri-A1), and phenylquinoline (Phe-A1).
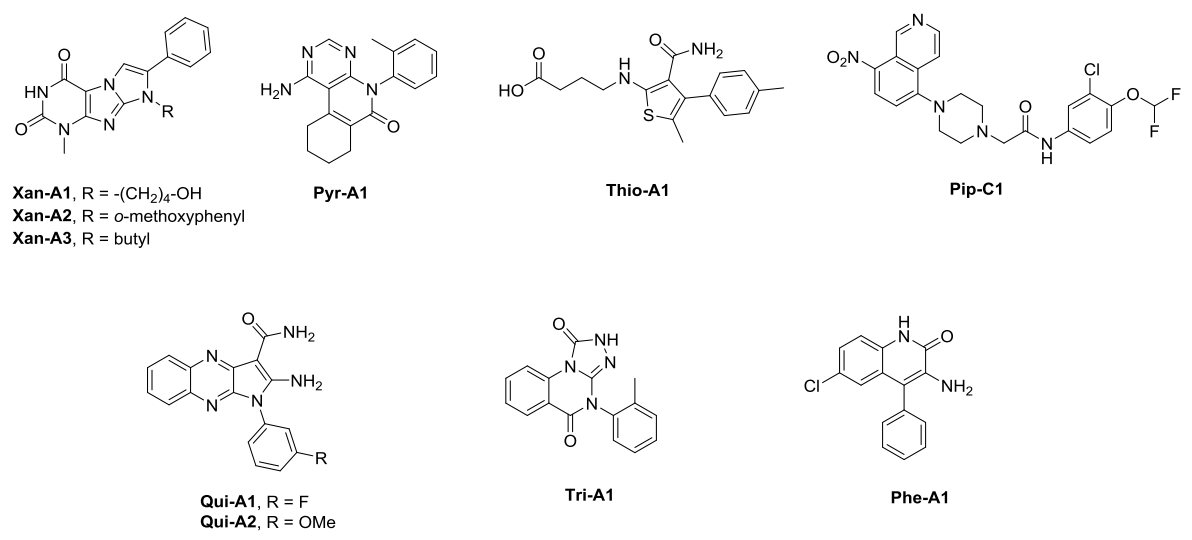

Figure 2. EphB4 tyrosine kinase inhibitors identified in our groups. ${ }^{49-51,53-54}$ The molecules are labeled by the first letters of their scaffold (Xan, Pyr, Thio, Pip, Qui, Tri, and Phe), followed by the letters $A, B$, and $C$ for type $I, I_{1 / 2}$, and II inhibitors, respectively.

In the next sections, we review the optimization campaigns started from Xan-A1, ${ }^{55-56}$ Pyr-A1 ${ }^{50}$ and Qui-A1 hits, ${ }^{57}$ with emphasis on their in depth in vitro and in vivo characterization, together with previously unpublished angiogenesis and fluorescence based assays.

\section{Optimization of the xanthine scaffold (Xan-A1-A3)}

To streamline the structure activity relationship (SAR) study of the xanthine scaffold (Xan), a modular synthetic approach towards these molecules was developed as shown in Scheme 1. The key intermediate 8-bromoxanthine 1 was obtained by condensation of commercially available cyanoacetic acid and methylurea or benzylurea in five steps. ${ }^{55} 8$ Bromoxanthine 1 was then alkylated with a variety of $\alpha$-halo ketones using $N, N$ diisopropylethylamine in dimethylformamide as solvent, providing the 8-bromo-3-alkyl-7-(2oxo-2-phenylethyl)xanthines 2 in good yields. Treatment of intermediates 2 with primary alkylamines or anilines in a sealed tube at $180{ }^{\circ} \mathrm{C}$ in ethanol afforded the desired imidazo$[1,2-f]$ xanthine derivatives Xan-A (for type I inhibitors) and Xan-B (type $I_{1 / 2}$ ) (Scheme 1). 


\section{Scheme $1^{\text {a }}$}

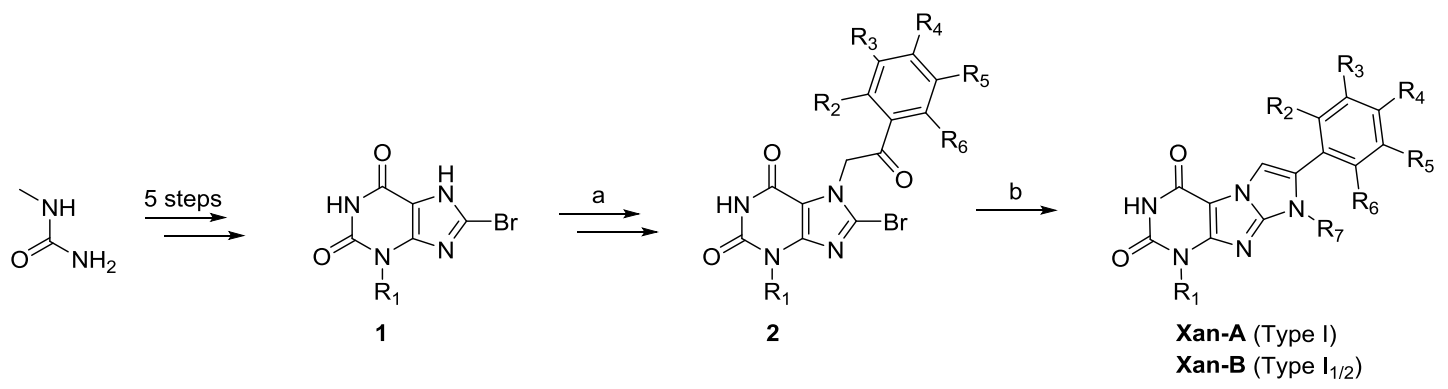

${ }^{a}$ Reagents and conditions: (a) $\alpha$-Halo ketone, DIPEA, DMF, $25^{\circ} \mathrm{C}, 17 \mathrm{~h}$; (b) Primary amine or aniline, $\mathrm{EtOH}$, sealed tube, reflux, $15 \mathrm{~h}$.

This effective synthetic approach yielded over 34 derivatives that enabled a detailed SAR study of the xanthine core. The inhibitory activity of the synthesized analogues was determined by a fluorescence resonance energy transfer (FRET) based enzymatic assay that quantifies inhibition of phosphorylation of a synthetic substrate of EphB4 at Km concentration of ATP. Moreover, cellular phosphorylation assays were performed with some of the derivatives, where murine embryonal fibroblast cells (MEF) were transfected with myctagged human EphB4. The cells were incubated with the corresponding inhibitor and stimulated with ehrinB2-Fc, to finally quantify the autophosphorylation of EphB4 via sandwich ELISA. 
Table 1. EphB4 inhibition data for type I xanthine derivatives

\begin{tabular}{|c|c|c|c|c|c|c|c|c|c|}
\hline Compound & $\mathrm{R}_{1}$ & $\mathrm{R}_{2}$ & $\mathrm{R}_{3}$ & $\mathrm{R}_{4}$ & $\mathrm{R}_{5}$ & $\mathrm{R}_{6}$ & $\mathrm{R}_{7}$ & $\begin{array}{c}\mathrm{IC}_{50}(\mathrm{nM}) \text { or } \% \text { of } \\
\text { inhibition in a } \\
\text { FRET } \\
\text { enzymatic assay }^{\mathrm{a}}\end{array}$ & $\begin{array}{l}\text { Cellular } \mathrm{IC}_{50} \\
\qquad(\mathrm{nM})^{\mathrm{b}}\end{array}$ \\
\hline Xan-A1 & $\mathrm{Me}$ & $\mathrm{H}$ & $\mathrm{H}$ & $\mathrm{H}$ & $\mathrm{H}$ & $\mathrm{H}$ & $\widehat{\mathrm{OH}}_{\mathrm{H}}$ & 7000 & 0 \\
\hline Xan-A2 & $\mathrm{Me}$ & $\mathrm{H}$ & $\mathrm{H}$ & $\mathrm{H}$ & $\mathrm{H}$ & $\mathrm{H}$ & & 3300 & $14 \%$ at $20 \mu \mathrm{M}$ \\
\hline Xan-A3 & $\mathrm{Me}$ & $\mathrm{H}$ & $\mathrm{H}$ & $\mathrm{H}$ & $\mathrm{H}$ & $\mathrm{H}$ & & 1900 & $<10 \%$ at $20 \mu \mathrm{M}$ \\
\hline Xan-A4 & $\mathrm{Bn}$ & $\mathrm{H}$ & $\mathrm{H}$ & $\mathrm{H}$ & $\mathrm{H}$ & $\mathrm{H}$ & & $>10000$ & n. d. \\
\hline Xan-A5 & $\mathrm{Bn}$ & $\mathrm{H}$ & $\mathrm{H}$ & $\mathrm{F}$ & $\mathrm{H}$ & $\mathrm{H}$ & & $>10000$ & n. d. \\
\hline Xan-A6 & $\mathrm{H}$ & $\mathrm{H}$ & $\mathrm{H}$ & $\mathrm{F}$ & $\mathrm{H}$ & $\mathrm{H}$ & & 5400 & n. d. \\
\hline Xan-A7 & $\mathrm{Me}$ & $\mathrm{H}$ & 1, 3-dioxol & $\mathrm{H}$ & $\mathrm{H}$ & $\mathrm{H}$ & & $>20000$ & n. d. \\
\hline Xan-A8 & $\mathrm{Me}$ & $\mathrm{H}$ & 1, 3-dioxol & $\mathrm{H}$ & $\mathrm{H}$ & $\mathrm{H}$ & & $42 \%$ at $10 \mu \mathrm{M}$ & n. d. \\
\hline Xan-A9 & $\mathrm{Me}$ & 1, 3-dioxol & $\mathrm{H}$ & $\mathrm{H}$ & $\mathrm{H}$ & $\mathrm{H}$ & & $30 \%$ at $10 \mu \mathrm{M}$ & n. d. \\
\hline $\begin{array}{l}\text { Xan-A10 } \\
\text { Xan-A11 } \\
\text { Xan-A12 }\end{array}$ & $\begin{array}{l}\mathrm{Me} \\
\mathrm{Me} \\
\mathrm{Me}\end{array}$ & $\begin{array}{c}\mathrm{OMe} \\
\mathrm{H} \\
\mathrm{H}\end{array}$ & $\underset{\mathrm{H}}{\mathrm{OM}}$ & $\begin{array}{c}\mathrm{H} \\
\mathrm{H} \\
\mathrm{OMe}\end{array}$ & $\begin{array}{l}\mathrm{H} \\
\mathrm{H} \\
\mathrm{H}\end{array}$ & $\begin{array}{l}\mathrm{H} \\
\mathrm{H} \\
\mathrm{H}\end{array}$ & & $\begin{array}{c}>10000 \\
36 \% \text { at } 10 \mu \mathrm{M} \\
>10000\end{array}$ & $\begin{array}{l}\text { n. } d . \\
\text { n. } d . \\
\text { n. } d .\end{array}$ \\
\hline Xan-A13 & $\mathrm{Me}$ & $\mathrm{Cl}$ & $\mathrm{H}$ & $\mathrm{H}$ & $\mathrm{H}$ & $\mathrm{H}$ & & 300 & 2200 \\
\hline Xan-A14 & $\mathrm{Me}$ & $\mathrm{H}$ & $\mathrm{H}$ & $\mathrm{H}$ & $\mathrm{Cl}$ & $\mathrm{H}$ & & $12 \%$ at $10 \mu \mathrm{M}$ & n. d. \\
\hline Xan-A15 & $\mathrm{Me}$ & $\mathrm{Me}$ & $\mathrm{H}$ & $\mathrm{H}$ & $\mathrm{H}$ & $\mathrm{H}$ & & 180 & n. d. \\
\hline Xan-A16 & $\mathrm{Me}$ & $\mathrm{H}$ & $\mathrm{Me}$ & $\mathrm{H}$ & $\mathrm{H}$ & $\mathrm{H}$ & & $>10000$ & n. d. \\
\hline $\begin{array}{l}\text { Xan-A17 } \\
\text { Xan-A18 } \\
\end{array}$ & $\begin{array}{l}\mathrm{Me} \\
\mathrm{Me}\end{array}$ & $\begin{array}{l}\mathrm{H} \\
\mathrm{H} \\
\end{array}$ & $\begin{array}{c}\mathrm{Me} \\
\mathrm{H}\end{array}$ & $\begin{array}{c}\mathrm{H} \\
\mathrm{Me}\end{array}$ & $\begin{array}{l}\mathrm{H} \\
\mathrm{H} \\
\end{array}$ & $\begin{array}{l}\mathrm{H} \\
\mathrm{H} \\
\end{array}$ & 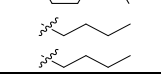 & $\begin{array}{l}37 \% \text { at } 10 \mu \mathrm{M} \\
38 \% \text { at } 10 \mu \mathrm{M}\end{array}$ & $\begin{array}{l}\text { n. d. } \\
\text { n. d. }\end{array}$ \\
\hline
\end{tabular}

First, the affinity of type I inhibitors Xan-A1-A3 was optimized (Table 1). The chemical edition of the molecule started at $R_{1}$ position, which modulates the interactions of the nitrogen substituent with the Ala700 residue of the binding pocket (Table 1, Xan-A4-A6). However, the exchange of the methyl group by a benzyl substituent (Xan-A4, A5) or a hydrogen (Xan-A6) resulted in a loss of the inhibitory activity compared to the parent hit molecules (Xan-A1, A2 and A3).

Since only around $20 \%$ of the human kinases possess a small gatekeeper residue, among them EphB4 with a threonine residue (Thr693), we modified the substitution pattern at the phenyl ring aiming to improve the affinity and selectivity. In contrast to previously developed EphB4 inhibitors (compound II, Figure 1), ${ }^{29-30}$ the presence of a dioxole ring or methoxy groups at different positions of the phenyl ring (Xan-A7-A12) significantly reduced the binding affinity. As the decrease of activity could be due to the limited space around the phenyl ring, less sterically demanding substituents such as chlorine and methyl groups were incorporated (Xan-A13-A18), resulting in the first nanomolar inhibitors, Xan-A13 and XanA15, bearing a chlorine and methyl group in ortho relative position respectively. The role of 
the methyl substituent was examined by performing an exhaustive conformational analysis using quantum mechanics. The presence of a methyl group in ortho relative position did not only restrict the accesible conformations of the molecule but also contributed to an energy gain in van der Waals interactions with the side chains of Val629(635), Ala645(651) and the gatekeeper residue Thr693(699), where the first three digits correspond to the aminoacid residue number in EphB4 and the digits in parenthesis to the ones in EphA3. Interestingly, the presence of the studied methyl substituent represents a common substitution pattern among kinase inhibitors. ${ }^{39}$

With the optimized type I inhibitors in hand, we embarked on the development of type $\mathrm{I}_{1 / 2}$ inhibitors that could establish hydrogen bond interactions with the conserved Glu664(670) and the backbone of the activation loop, Asp758(764) (Table 2). Thus, hydroxyl groups were introduced in different positions of the benzene ring (Xan-B1-B6). A meta relative substitution (Xan-B3, B4) showed the highest inhibition with $I C_{50}$ values in the FRET enzymatic assay of 368 and $691 \mathrm{nM}$ respectively. In those cases, the replacement of the anisidine (Xan-B1, B3, B5) for a butyl side chain (Xan-B2, B4, B6) had a limited influence in the inhibitory affinity, consistent with the trend observed for the type I xanthine inhibitors (Table 1).

Table 2. EphB4 inhibition data for type $I_{1 / 2}$ xanthine derivatives

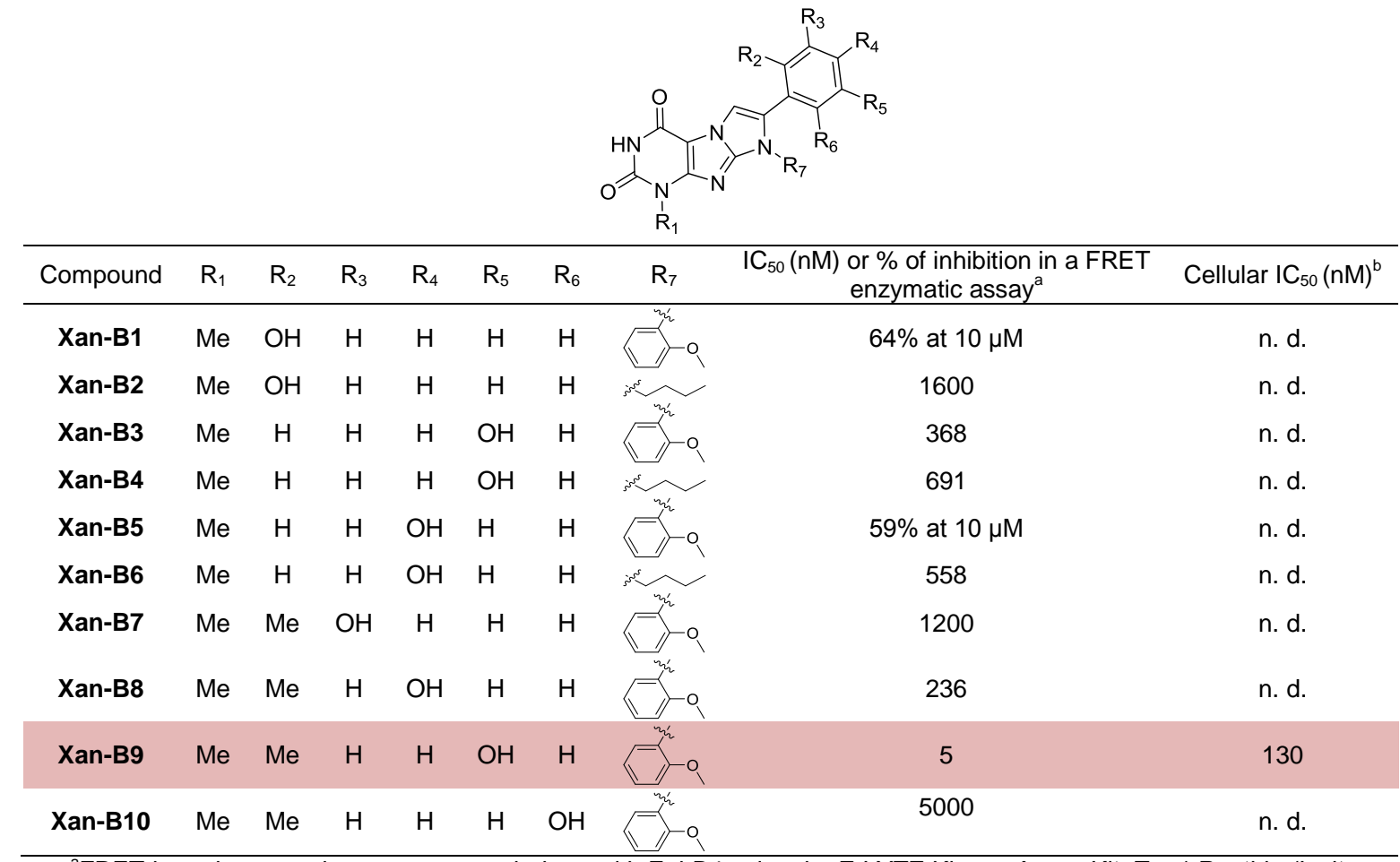

${ }^{a}$ FRET-based enzymatic assay was carried out with EphB4 using the Z-LYTE Kinase Assay Kit-Tyr 1 Peptide (Invitrogen) following the vendor instructions. ${ }^{b}$ Cell $I_{50}$ values were measured in a cellular phosphorylation assay using MEF cells overexpressing EphB4 at Proqinase. n. d.: not determined. The highlighted entry represents the most potent compound.

The combination of the most promising substitution patterns, methyl substituent in ortho (Table 1, Xan-A15) and hydroxyl group in meta relative position (Table 2, Xan-B3, B4), yielded compound Xan-B9, which displayed a 1000 -fold higher affinity (an $\mathrm{IC}_{50}$ value of 5 $\mathrm{nM}$ in the FRET enzymatic assay) and an increased ligand efficiency $(0.37 \mathrm{kcal} / \mathrm{mol})$ compared to the original hits Xan-A1 and Xan-A2 (ligand effciency of $0.26 \mathrm{kcal} / \mathrm{mol}$ ). Unfortunately, a significant reduction (almost two orders of magnitude) of the inhibitory activity of this compound was observed in cellular assays $\left(\mathrm{IC}_{50}\right.$ value of $130 \mathrm{nM}$, column 10 , 
Table 2), which could be a consequence of reduced permeability or increased efflux in the cell. In addition, phenols are known to have poor pharmacokinetic properties as they can undergo glucuronidation during phase II metabolism. ${ }^{58-59}$ These data prompted us to investigate the cell permeability of compounds Xan-A2, Xan-A3 and Xan-B9 (Table 3) in the Caco-2 model, which expresses many transport proteins present in epithelial cells of the small intestine and provides insights on the absorption across intestinal tissues in vivo.

Table 3. Cell permeability measurements using the Caco-2 model.

\begin{tabular}{|c|c|c|c|c|c|c|c|}
\hline \multirow{2}{*}{ Compound } & \multicolumn{2}{|c|}{ \%Recovery } & \multicolumn{2}{|c|}{$\mathrm{P}_{\text {app }}\left(\mathrm{x} 10^{-6} \mathrm{~cm} / \mathrm{s}\right)^{\mathrm{a}}$} & \multirow{2}{*}{$\begin{array}{l}\text { Efflux } \\
\text { ratio }^{\mathrm{b}}\end{array}$} & \multirow{2}{*}{$\begin{array}{l}\text { Permeability } \\
\text { classification }^{c}\end{array}$} & \multirow{2}{*}{$\begin{array}{c}\text { Significant } \\
\text { efflux }^{d}\end{array}$} \\
\hline & $A-B$ & $B-A$ & $A-B$ & B-A & & & \\
\hline Xan-A2 & 71 & 76 & 32.3 & 35.8 & 1.1 & High & No \\
\hline Xan-A3 & 69 & 78 & 42.5 & 42.5 & 1.0 & High & No \\
\hline Xan-B9 & 51 & 74 & 3.13 & 23.0 & 7.3 & High & Yes \\
\hline
\end{tabular}

${ }^{a}$ Apparent permeability $\left(P_{\text {app }}\right)$ is measured from the apical side to the basolateral side $(A-B)$ and from the basolateral side to the apical side $(B-A) \cdot{ }^{b}$ Efflux ratio $=\left(P_{a p p} B \rightarrow A\right) /\left(P_{a p p} A \rightarrow B\right)$. ${ }^{c}$ Permeability classification : low $=\left(P_{\text {app }} A \rightarrow B\right)<1.0 \times 10^{-6} \mathrm{~cm} / \mathrm{s}$; high $=\left(P_{\text {app }} A \rightarrow B\right)>1.0 x$ $10^{-6} \mathrm{~cm} / \mathrm{s}$. ${ }^{d}$ Significant efflux: efflux ratio $>3.0$ and $\left(P_{\text {app }} B \rightarrow A\right)>1.0 \times 10^{-6} \mathrm{~cm} / \mathrm{s}$.

Interestingly, the hit compounds Xan-A2 and Xan-A3 (Table 1) having an undecorated phenyl ring showed no significant efflux, whereas Xan-B9 (Table 2), bearing a methyl group in ortho relative position and a hydroxyl in meta, was significantly effluxed by Pglycoprotein transporters, explaining the discrepancy between enzymatic $\left(\mathrm{IC}_{50}=5 \mathrm{nM}\right)$ and cellular $\left(\mathrm{IC}_{50}=130 \mathrm{nM}\right)$ assays (Table 2). In addition, compound Xan-A3 presented higher membrane permeation than Xan-A2, which could be attributed to the presence of the butyl side chain at position $\mathrm{R}_{7}$ (Table 1). Thus, a next generation of xanthine inhibitors bearing an alkyl substituent in that position were synthesized in order to improve the pharmacological profile of the molecules (Table 4).

Table 4. EphB4 inhibition data for type $I$ and $I_{1 / 2}$ xanthine derivatives with improved pharmacological profile.

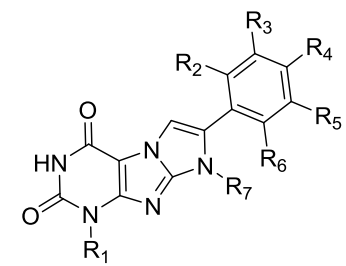

\begin{tabular}{|c|c|c|c|c|c|c|c|c|c|}
\hline Cmp & $\begin{array}{l}\text { Type of } \\
\text { binding }\end{array}$ & $\mathrm{R}_{1}$ & $\mathrm{R}_{2}$ & $\mathrm{R}_{3}$ & $\mathrm{R}_{4}$ & $\mathrm{R}_{5}$ & $\mathrm{R}_{7}$ & $\begin{array}{c}\mathrm{IC}_{50}(\mathrm{nM}) \text { or \% of inhibition in a } \\
\text { FRET } \\
\text { enzymatic assay }^{\mathrm{a}}\end{array}$ & $\begin{array}{l}\text { Cellular } \\
\text { IC }_{50} \\
(\mathrm{nM})^{\mathrm{b}}\end{array}$ \\
\hline Xan-A19 & I & $\mathrm{Me}$ & $\mathrm{Me}$ & $\mathrm{H}$ & $\mathrm{H}$ & $\mathrm{H}$ & & 56 & 50 \\
\hline Xan-A20 & I & $\mathrm{Me}$ & $\mathrm{Me}$ & $\mathrm{H}$ & $\mathrm{H}$ & $\mathrm{H}$ & & 177 & 230 \\
\hline Xan-A21 & I & $\mathrm{Me}$ & $\mathrm{Me}$ & $\mathrm{H}$ & $\mathrm{H}$ & $\mathrm{H}$ & & 1300 & n.d. \\
\hline Xan-A22 & i & $\mathrm{Me}$ & $\mathrm{Me}$ & $\mathrm{H}$ & $\mathrm{F}$ & $\mathrm{H}$ & & 91 & 68 \\
\hline Xan-A23 & i & $\mathrm{Me}$ & $\mathrm{H}$ & $\mathrm{H}$ & $\mathrm{H}$ & $\mathrm{Cl}$ & & $22 \%$ at $10 \mu \mathrm{M}$ & n.d. \\
\hline Xan-A24 & I & $\mathrm{Me}$ & $\mathrm{Cl}$ & $\mathrm{H}$ & $\mathrm{H}$ & $\mathrm{H}$ & & 182 & 270 \\
\hline Xan-A25 & i & $\mathrm{Me}$ & $\mathrm{CF}_{3}$ & $\mathrm{H}$ & $\mathrm{H}$ & $\mathrm{H}$ & & $15 \%$ at $10 \mu \mathrm{M}$ & n.d. \\
\hline Xan-A26 & I & $\mathrm{Me}$ & $\mathrm{Me}$ & $\mathrm{H}$ & $\mathrm{H}$ & $\mathrm{Me}$ & & $49 \%$ at $10 \mu \mathrm{M}$ & n.d. \\
\hline Xan-B11 & $\mathrm{l}_{1 / 2}$ & $\mathrm{Me}$ & $\mathrm{Me}$ & $\mathrm{H}$ & $\mathrm{H}$ & indazole & w & 14 & 150 \\
\hline
\end{tabular}

${ }^{a}$ FRET-based enzymatic assay was carried out with EphB4 using the Z-LYTE Kinase Assay Kit-Tyr 1 Peptide (Invitrogen) following the vendor instructions. ${ }^{b}$ Cell $I_{50}$ values were measured in a cellular phosphorylation assay using MEF cells overexpressing EphB4 at Proqinase. n. d.: not determined. The highlighted entries represent the most potent compounds.

The substitution of the anisidine side chain in Xan-A15 (Table 1) by a butyl group resulted in compound Xan-A19 with an $\mathrm{IC}_{50}$ value of $56 \mathrm{nM}$. Extension of the butyl chain by one (Xan-A20) or two (Xan-A21) additional carbon atoms led to a decrease in activity due to the hydrophobic effect, as the mentioned alkyl chains point towards the solvent. The addition of a fluorine atom at position $\mathrm{R}_{4}$ (Xan-A22) did not yield an improved potency with an $\mathrm{IC}_{50}$ value of $91 \mathrm{nM}$. However, the addition of a chlorine atom at $R_{5}$ (Xan-A23) or the replacement 
of the methyl group in ortho relative position by a chlorine atom (Xan-A24) or a trifluoromethyl moiety (Xan-A25) led to lower binding affinity values, probably due to steric effects and less favourable van der Waals interactions as already seen in Table 1 (Xan-A9, $\mathbf{A 1 0}$ and A13). Along the same lines, the bis-ortho substitution in xanthine Xan-A26 dramatically decreased the potency, bringing the $\mathrm{IC}_{50}$ value to the micromolar level.

The phenol moiety of the type $I_{1 / 2}$ compound Xan-B9 which had showed significant efflux in cells (Table 3), was replaced by an indazole group, able to provide a similar hydrogen bonding pattern as well as an improved bioavailability profile. ${ }^{58}$ As such, Xan-B11 derivative showed an $\mathrm{IC}_{50}$ value in vitro of $14 \mathrm{nM}$.

As anticipated, the replacement of the anisidine to a butyl side chain led to compounds with nanomolar levels of inhibitory activity in cells (Xan-A19, A20, A22 and A24), which correlates with the potencies measured in the enzymatic assays. Unfortunately, the type $I_{1 / 2}$ compound Xan-B11 showed a ten-fold decrease in inhibition in cells overexpressing EphB4 with an $\mathrm{IC}_{50}$ value of $150 \mathrm{nM}$. This being the case, the cell permeability of compounds Xan-A19 and Xan-B11 was evaluated on Caco-2 monolayers (Table 5). As already predicted by the cell based inhibition (Table 4), compound Xan-A19 was not effluxed by transport proteins, in contrast to Xan-B11, which showed a significant efflux.

Table 5. Cell permeability measurements using the Caco-2 model.

\begin{tabular}{|c|c|c|c|c|c|c|c|}
\hline \multirow{2}{*}{ Compound } & \multicolumn{2}{|c|}{ \%Recovery } & \multicolumn{2}{|c|}{$P_{\text {app }}\left(x 10^{-6} \mathrm{~cm} / \mathrm{s}\right)^{a}$} & \multirow{2}{*}{$\begin{array}{l}\text { Efflux } \\
\text { ratio }^{b}\end{array}$} & \multirow{2}{*}{$\begin{array}{l}\text { Permeability } \\
\text { classification }^{c}\end{array}$} & \multirow{2}{*}{$\begin{array}{l}\text { Significant } \\
\text { efflux }^{d}\end{array}$} \\
\hline & $A-B$ & $B-A$ & $A-B$ & B-A & & & \\
\hline Xan-A19 & 85 & 89 & 42.7 & 28.1 & 0.7 & High & No \\
\hline Xan-B11 & 84 & 96 & 8.02 & 49.0 & 6.1 & High & Yes \\
\hline
\end{tabular}

${ }^{a}$ Apparent permeability $\left(P_{\text {app }}\right)$ is measured from the apical side to the basolateral side $(A-B)$ and from the basolateral side to the apical side $(B-A) .{ }^{b}$ Efflux ratio $=\left(P_{\text {app }} B \rightarrow A\right) /\left(P_{\text {app }} A \rightarrow B\right)$. ${ }^{c}$ Permeability classification : low $=\left(P_{\text {app }} A \rightarrow B\right)<1.0 \times 10^{-6} \mathrm{~cm} / \mathrm{s}$; high $=\left(P_{\text {app }} A \rightarrow B\right)>1.0 x$ $10^{-6} \mathrm{~cm} / \mathrm{s}$. ${ }^{d}$ Significant efflux: efflux ratio $>3.0$ and $\left(P_{\text {app }} B \rightarrow A\right)>1.0 \times 10^{-6} \mathrm{~cm} / \mathrm{s}$.

\subsection{Confirmation of the binding mode by protein X-ray crystallography}

The binding modes of the most potent type I compound Xan-A19 (Table 4) and the two type $I_{1 / 2}$ Xan-B9 (Table 2) and Xan-B11 inhibitor (Table 4) were confirmed by high resolution X-ray crystallography in complex with EphA3, a very similar protein to EphB4 that shares 32 out of 36 residues of the ATP binding site (Figure 3 ). The binding modes are essentially identical to that predicted in silico. ${ }^{49}$ In the three inhibitors, the pyrimidine ring forms two hydrogen bonds with the hinge region mimicking the adenosine moiety of ATP, whereas the phenyl ring that has been modified throughout the SAR study is located in the hydrophobic back pocket of the protein.

Inhibitors Xan-B9 and Xan-B11 present the prototypical hydrogen bond pattern of type $\mathrm{I}_{1 / 2}$ inhibitors accepting a hydrogen bond from the backbone $\mathrm{NH}$ of Asp758(764) of the activation loop and donating a hydrogen bond to the side chain of Glu664(670) via their phenol (Figure 3, A) or indazole (Figure 3, B) substituents, respectively. Interestingly, the anisidine side chain in Xan-B9 points outside of the binding pocket, in analogy to the butyl side chains of compounds Xan-A19 and Xan-B11 (Figure 3, D). 
A)

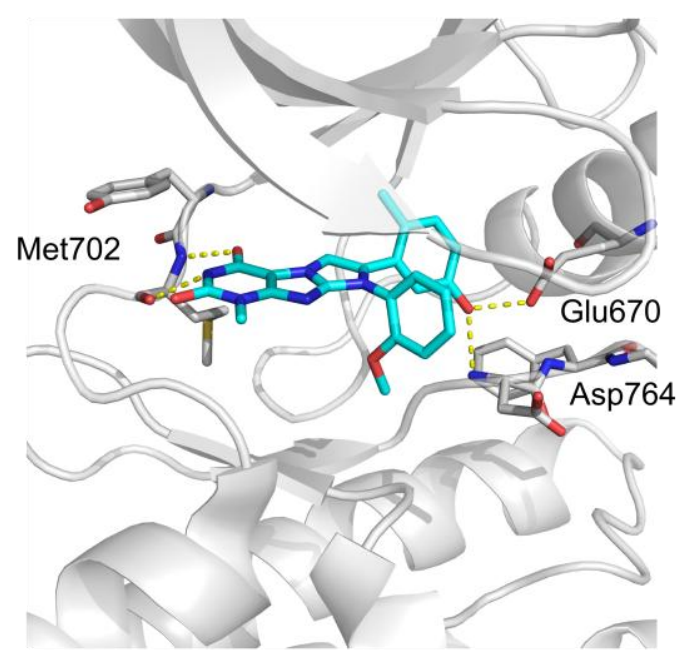

C)

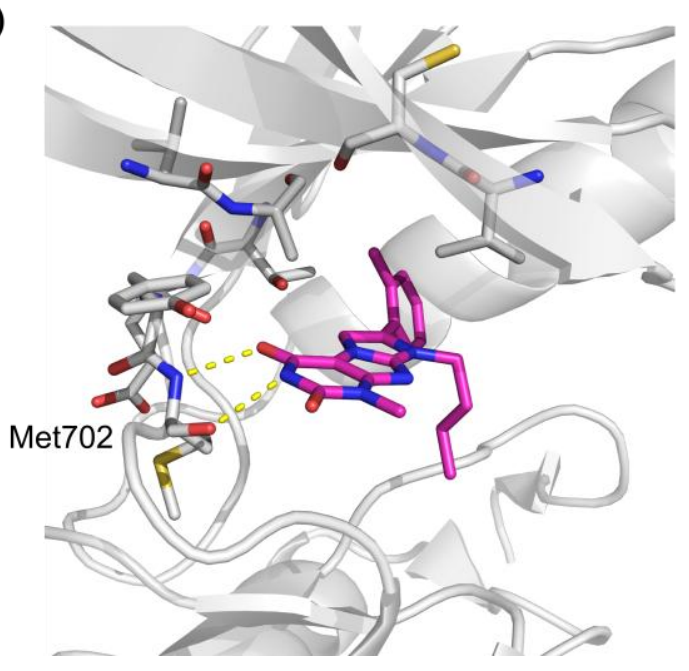

B)

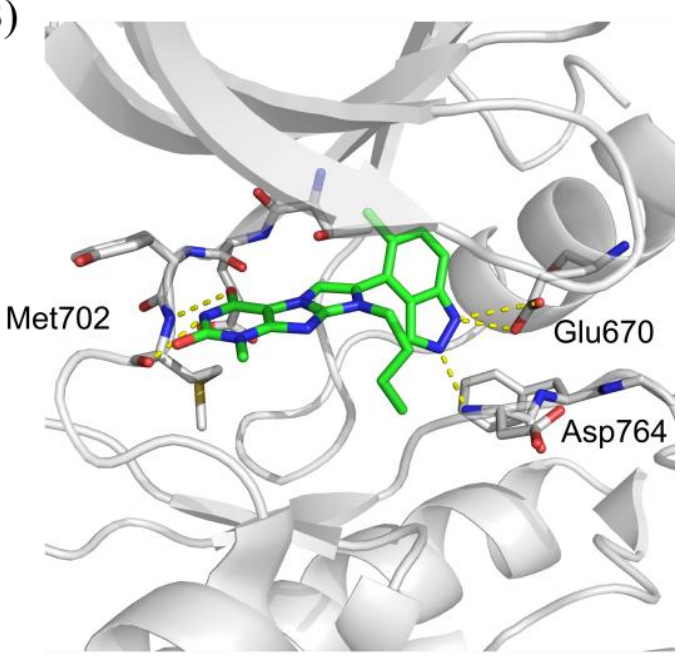

D)

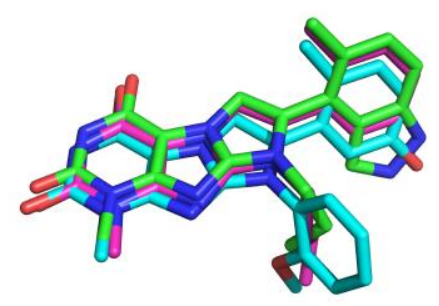

Figure 3. A, B) Crystal structures of the catalytic domain of the tyrosine kinase EphA3 in its DFG-in conformation in complex with the type $\mathrm{I}_{1 / 2}$ inhibitors Xan-B9 (PDB code 4GK2) and Xan-B11 (PDB code 4GK4) respectively. Yellow dashed lines represent intermolecular hydrogen bonds. The side chains mentioned in the text and the inhibitors are shown as sticks. C) Crystal structures of the catalytic domain of the tyrosine kinase EphA3 in its DFG-in conformation in complex with the type I inhibitor Xan-A19 (PDB code 4GK3). Dashed lines represent intermolecular hydrogen bonds. The residues that establish van der Waals interactions with the methyl substituent of the phenyl ring are shown as sticks. D) Superposition of compounds Xan-B9 (in cyan), Xan-B11 (in green) and Xan-A19 (in magenta).

\subsection{Selectivity profile}

The selectivity profile of the nanomolar inhibitors Xan-B9 and Xan-A19 was determined against a panel of 124 kinases. These xanthine derivatives show a good selectivity for tyrosine kinases with a threonine residue as gatekeeper (Figure 4).

Interestingly, Xan-A19 and Xan-B9 show a similar selectivity profile to Dasatinib, ${ }^{60}$ as they mainly target the tyrosine kinase family and have common targets among the most inhibited kinases, including Src, Lck, Abl, Yes1 and several Eph kinases (EphA3, A5 and A8). Remarkably, our inhibitors are less promiscuous and thus are likely to be less toxic than the FDA approved drug dasatinib. ${ }^{60}$ However, it should be noted that the selectivity of dasatinib was addressed against a broader panel of kinases (442 kinases). 

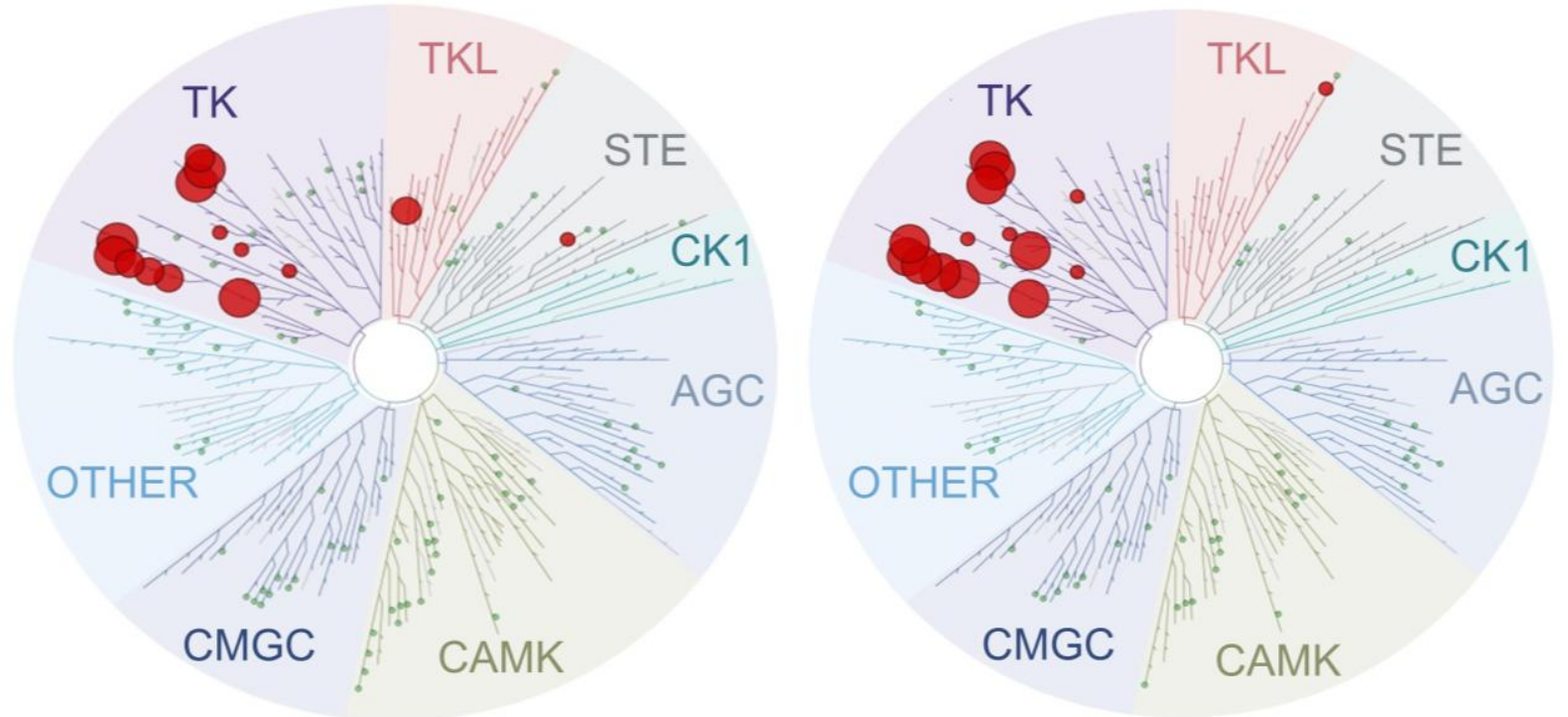

Strong inhibition

- Medium inhibition

- Low inhibition

- No inhibition

Figure 4. Selectivity profile of compound Xan-A19 (left) and Xan-B9 (right). Measurements were performed at the University of Dundee using a $\left[\mathrm{Y}^{-}{ }^{33} \mathrm{P}\right] \mathrm{ATP}$ based enzymatic assay at $3 \mu \mathrm{M}$ concentration of compound Xan-A19 and $1 \mu \mathrm{M}$ of compound XanB9. The affinity is defined as strong, medium and low (corresponding to $<10 \%, 10-30 \%$, and $30-70 \%$ of remaining activity with respect to a DMSO control). The dendrogram was obtained from KinomeScan using the KinomeTree software.

\subsection{Antiproliferative activity}

As mentioned in the introduction, EphB4 overexpression has been linked to several types of cancer, including breast, ${ }^{11}$ colon $^{13}$ and ovarian. ${ }^{16}$ Thus, the antiproliferative activity of compound Xan-B9 (Table 2) was assessed in the NCl-60 cancer cell line panel (Figure 5). Remarkable growth inhibition values were obtained against central nervous system (SNB-75, $128 \mathrm{nM}$ ), leukemia (K-562, $309 \mathrm{nM}$ ) and breast (HS 578T,562 nM) cancer cell lines. Interestingly, Xan-B9 shows a similar antiproliferative activity pattern as that of dasatinib despite presenting lower inhibition values, and therefore, lower toxicity, which might be beneficial when pursuing these compounds towards clinical development (Figure 5). 


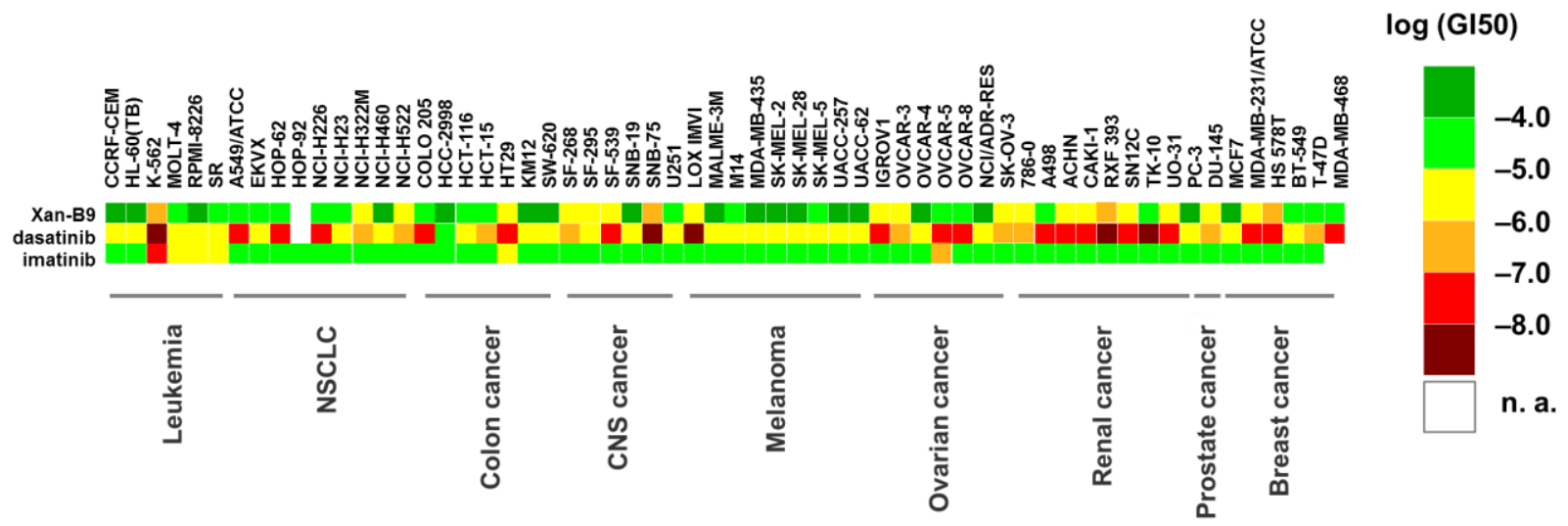

Figure 5. The antiproliferative activity of xanthine Xan-B9 in the $\mathrm{NCl}-60$ cancer cell panel is shown together with the growth inhibition of two anticancer drugs (dasatinib and imatinib). The growth inhibition is shown as a matrix with cell lines and compounds arranged vertically and horizontally, respectively. The legend bar shows the color coding which reflects the $\log \left(\mathrm{GI}_{50}\right)$ value, with red and green indicating high and low cytotoxicity, respectively.

Moreover, compounds Xan-B9, A19, A20, A22, A24 and B11 were incubated in the presence of patient-derived tumor cell lines (including colon, lung, kidney, pancreas, prostate and stomach cancer cells) using a propidium iodide-based proliferation assay and dasatinib as reference (Oncotest, Figure 6). Our xanthine series presented $\mathrm{Gl}_{50}$ values in the low micromolar range.

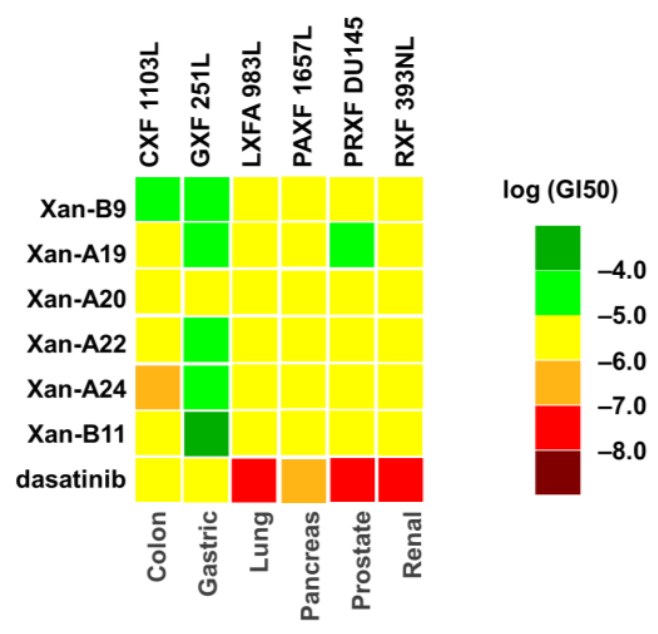

Figure 6. Anti-proliferative activity against six patient-derived tumor cell lines. $\mathrm{GI}_{50}$ values were determined at Oncotest using a modified propidium iodide assay. Measurements were done after 4 days of incubation with the corresponding compound. The growth inhibition is shown as a matrix with cell lines and compounds arranged vertically and horizontally, respectively. The legend bar shows the color coding which reflects the $\log \left(\mathrm{Gl}_{50}\right)$ value, with red and green indicating high and low cytotoxicity, respectively. 


\subsection{Cellular angiogenesis assay}

Neovascularization plays a role in several pathological conditions, including tumor growth, arthritis, and choroidal neovascularization. In particular, EphB4-ephrinB2 signaling has been associated to angiogenesis and blood vessel maturation. ${ }^{61}$ In fact, the EphB4 inhibitor NVP-BHG712 (VII, Figure 1), ${ }^{36}$ was able to inhibit vascular endothelial growth factor (VEGFR)-driven angiogenesis and the ephrine inhibitors ONC-101 (VIII, Figure 1) and ONC102 have also been proven to influence angiogenesis. ${ }^{62}$

Thus, we decided to examine the efficacy of some of our xanthine inhibitors on tube formation via an in vitro matrigel angiogenesis assay. Endothelial cells from human umbilical cords are able to differentiate and form capillary-like structures on Matrigel ${ }^{\mathrm{TM}}$, which is a protein mixture that resembles the complex extracellular environment found in tissues. ${ }^{63}$ Endothelial cells were incubated at $1 \mu \mathrm{M}$ concentration of the compounds, where no effect on cell proliferation was observed, and tube length, total number of branching points and total number of loops were quantified and compared to the control cells (Figure 7). Xan-B8 was the most potent compound, being able to significantly reduce the branching points of newly formed tubes by $87 \%$ as well as the number of loops (97\%) in the differentiated endothelial cells, followed by Xan-B9 and Xan-A19 (Figure 7).
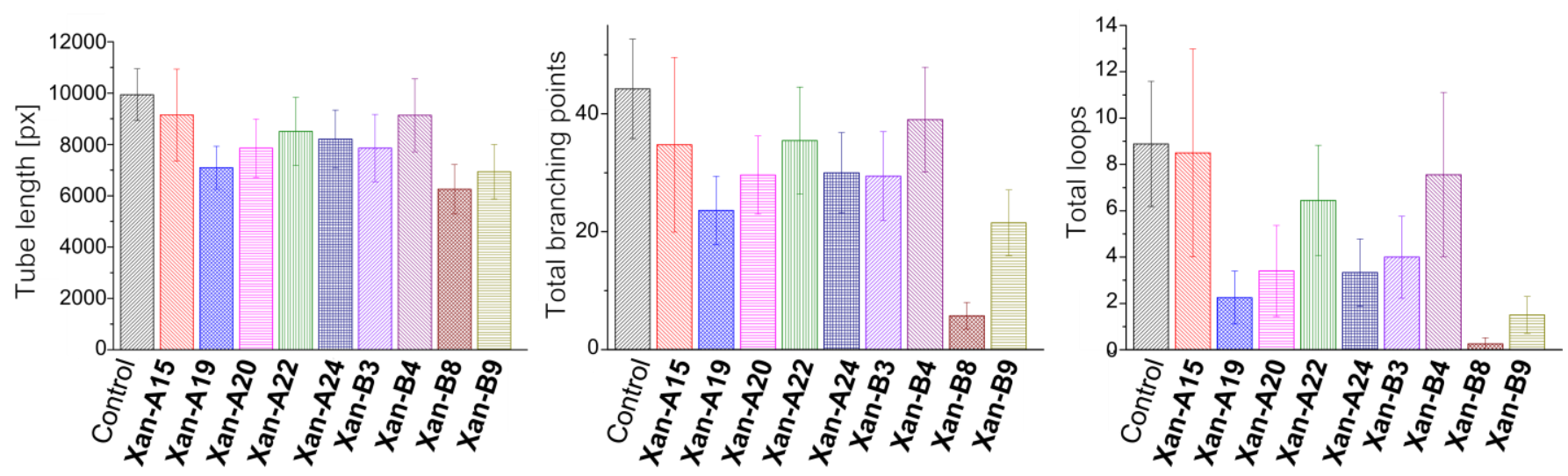

Figure 7. In vitro angiogenesis assay on tube formation. Compounds were incubated with HUEVEC cells seeded on matrigel for $15 \mathrm{~h}$. Tube length (left), total branching points (middle) and total loops (right) were quantified. All measurements were done at least in triplicate, and their SEM values are indicated as error bars.

The remarkable effect observed for Xan-B8 led us to perform dose response curves, obtaining $\mathrm{IC}_{50}$ values of $1.7,0.191$ and $0.071 \mu \mathrm{M}$ for the tube length, total branching points and total loops respectively. Moreover, in vivo tests were conducted in the retina of the mice after administering the compounds Xan-A19 and Xan-B8 i.p. at a concentration of $1 \mathrm{mg} / \mathrm{Kg}$. The number of vascular sprouts as well as the number of vascular branching points were quantified in the retinas of the mice. Surprisingly, even if the two inhibitors showed remarkable inhibition of angiogenesis in vitro (Figure 7), the degree of branching in the developing vasculature of the mice seemed to increase after compound treatment, whereas the number of vascular sprouts remained almost constant (see Supporting Information for further details). These results could be explained by the presence of other Eph receptors in the mice retina that were absent in the in vitro assay or by a possible activation of alternative signaling pathways upon Eph inhibition by the inhibitors. Thus, further in vivo experiments are underway in an effort to further rationalize the obtained results. 


\section{Optimization of the pyrimidoisoquinolinone scaffold Pyr- A1}

Pyrimidoisoquinolinone Pyr-A1, with an $\mathrm{IC}_{50}$ value of $9.4 \mu \mathrm{M}$ in in vitro FRET assays was identified using the in silico procedure ALTA (Figure 2).$^{50}$ Based on the thorough SAR study performed with the xanthine inhibitors, a hydroxyl group in meta relative position was incorporated in the phenyl ring (in an analogous manner to Xan-B9, Table 2), resulting in compound Pyr-B1, which showed an over 30 fold improvement in binding affinity with an $\mathrm{IC}_{50}$ value of $300 \mathrm{nM}$.

The synthesis of quinoline Pyr-B1 started from the reported acetal $3,{ }^{64}$ which was reacted with 2-methoxy-2-methylaniline under microwave irradiation to afford compound 4 as a mixture of tautomers. ${ }^{65}$ Subsequent reaction with malononitrile provided intermediate $\mathbf{5}$ that underwent cyclization in the presence of formamide. ${ }^{66}$ Final demethylation of the methoxy group in intermediate $\mathbf{6}$ was obtained in the presence of $\mathrm{BBr}_{3}$, affording the final inhibitor PyrB1.

\section{Scheme $2^{\mathrm{a}}$}<smiles>CC1(C)OC(=O)C2=C(CCCC2)O1</smiles>

3<smiles>Cc1ccc(O[W])cc1NC(=O)C1=C(O)CCCC1</smiles>

4<smiles>COc1ccc(C)c(NC(=O)C2CCCCC2=O)c1</smiles><smiles>COc1ccc(C)c(-n2c(N)c(C#N)c3c(c2=O)CCCC3)c1</smiles>

5

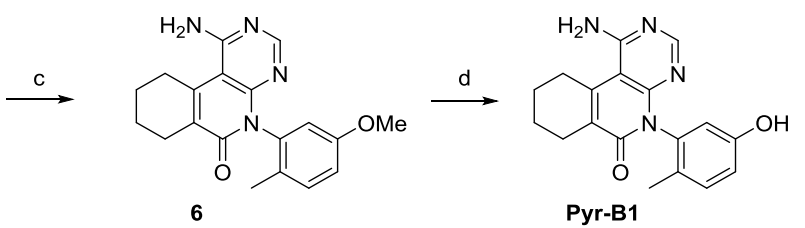

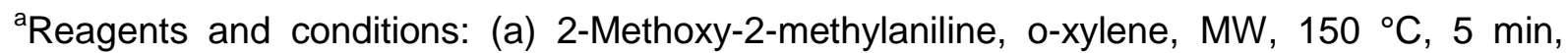
$46 \%$. (b) Malononitrile, piperidine, $\mathrm{EtOH}, 100{ }^{\circ} \mathrm{C}, 1-2 \mathrm{~h}, 82 \%$. (c) Formamide, $210^{\circ} \mathrm{C}, 7 \mathrm{~h}$, $62 \%$. (d) $\mathrm{BBr}_{3}, \mathrm{CH}_{2} \mathrm{Cl}_{2}, 25^{\circ} \mathrm{C}, 16 \mathrm{~h}, 28 \%$.

\subsection{Confirmation of the binding mode by protein $X$-ray crystallography}

The binding mode obtained by docking and MD simulations ${ }^{50}$ was confirmed by solving the X-ray structure of compound Pyr-B1 in complex with EphA3 at a resolution of $1.7 \AA$. The inhibitor binds to EphA3 in its DFG-in conformation forming four intermolecular hydrogen bonds, two with the hinge region, one with the activation loop, and a fourth one with the conserved glutamic acid residue, a characteristic hydrogen bonding pattern among type $I_{1 / 2}$ inhibitors (Figure 8). ${ }^{39}$ 


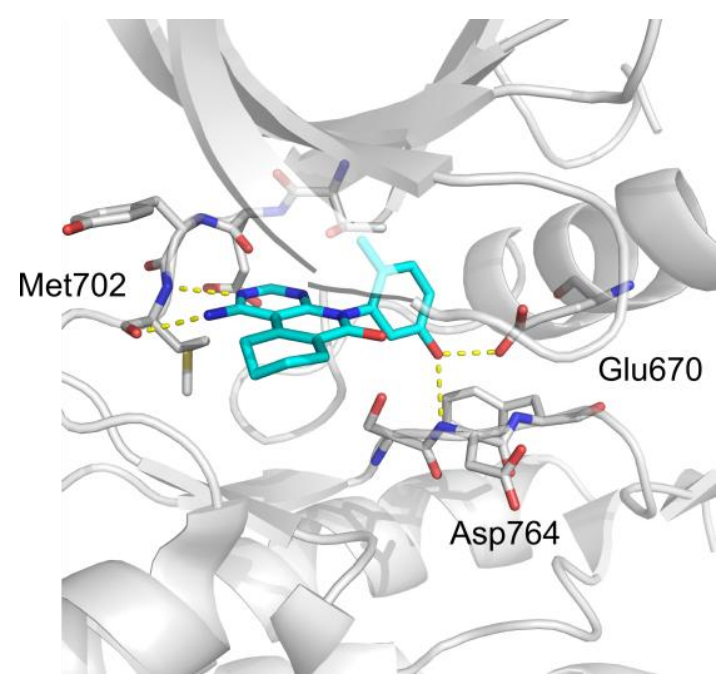

Figure 8. Crystal structure of the catalytic domain of the tyrosine kinase EphA3 in its DFG-in conformation in complex with the type $\mathrm{I}_{1 / 2}$ inhibitor Pyr-B1 (PDB code 4G2F). Yellow dashed lines represent intermolecular hydrogen bonds and the side chains mentioned in the text and the inhibitor are shown as sticks in grey and cyan respectively.

\subsection{Selectivity profile}

The selectivity of the nanomolar inhibitor Pyr-B1 was determined in a panel of 453 protein kinases by an in vitro competition binding assay that reports binding affinity without the need of ATP (KINOMEscan at DiscoveRx). ${ }^{67}$ Compound Pyr-B1 presents a good selectivity profile, since it is only able to inhibit a few proteins outside the tyrosine kinase family (Figure 9).

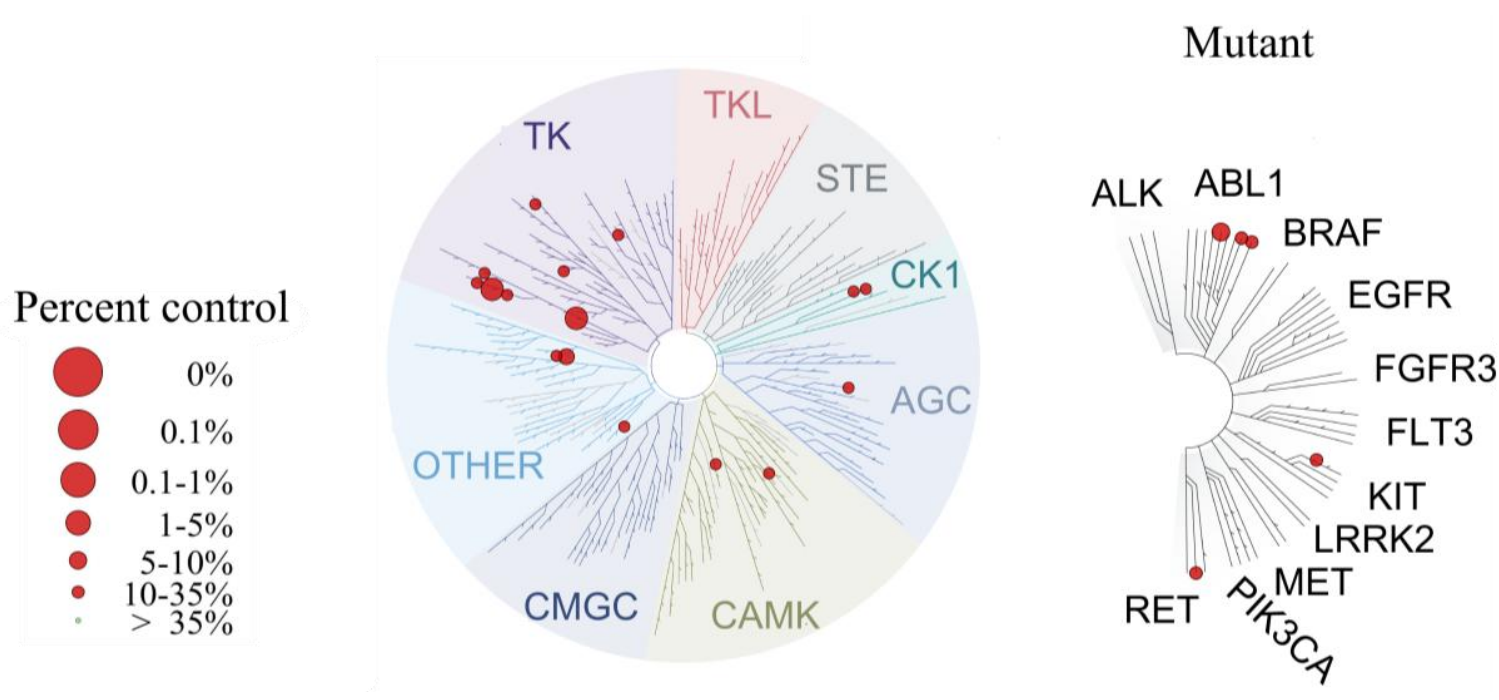

Figure 9. Selectivity profile of compound Pyr-B1 tested on a panel of 453 protein kinases at DiscoveRx. Measurements were performed at a $1 \mu \mathrm{M}$ concentration of the inhibitor. The affinity is defined with respect to a DMSO control. The dendrogram was obtained from KinomeScan using the KinomeTree software. 


\subsection{Cellular angiogenesis assay}

Due to the implications of EphB4-ephrinB2 signaling in angiogenesis and blood vessel maturation $^{61}$ the efficacy of Pyr-B1 was examined on tube formation via an in vitro matrigel angiogenesis assay (Figure 10). Unfortunately, no significant effect was found for Pyr-B1 in comparison to the xanthine derivative Xan-B8 (Figure 7), which could be due to cell permeability or efflux issues.
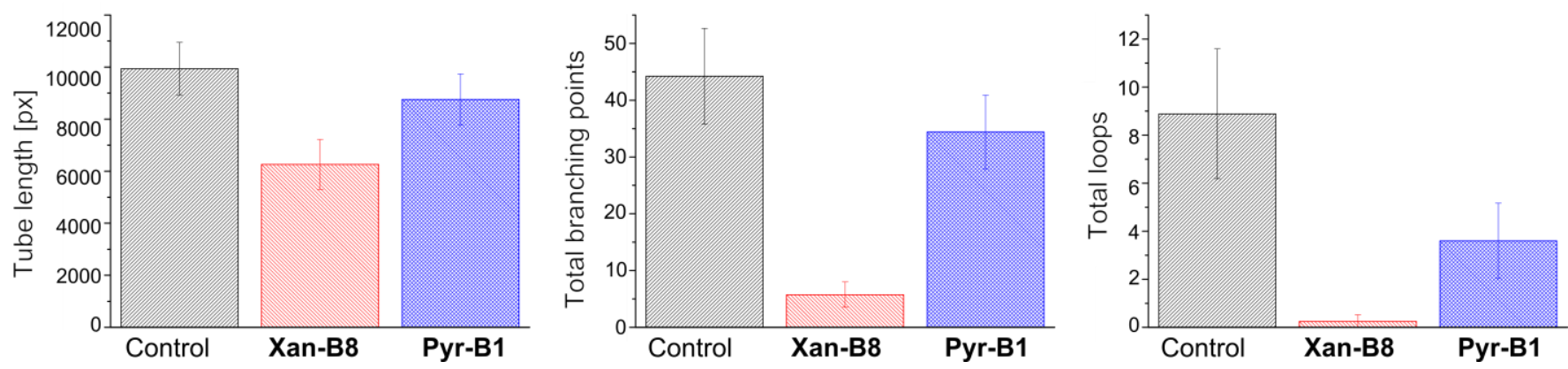

Figure 10. In vitro angiogenesis assay on tube formation. Compounds were incubated with HUEVEC cells seeded on matrigel for $15 \mathrm{~h}$. Tube length (left), total branching points (middle) and total loops (right) were quantified. All measurements were done at least in triplicate, and their SEM values are indicated as error bars.

\section{Optimization of the pyrrolo[3, 2-b]quinoxaline scaffold Qui-A1,A2}

Our third medicinal chemistry optimization campaign aimed at the design of novel and potent, type $I_{1 / 2}$ and II tyrosine kinase inhibitors using the crystal structure of two type I inhibitors bearing a quinoxaline scaffold (Qui-A1 and Qui-A2, Figure 2). These molecules were discovered by automated docking, ${ }^{54}$ and their in silico predicted binding mode was confirmed by X-ray diffraction analysis of the catalytic domain of EphA3 in complex with both Qui-A1 and Qui-A2 (Figure 11). 

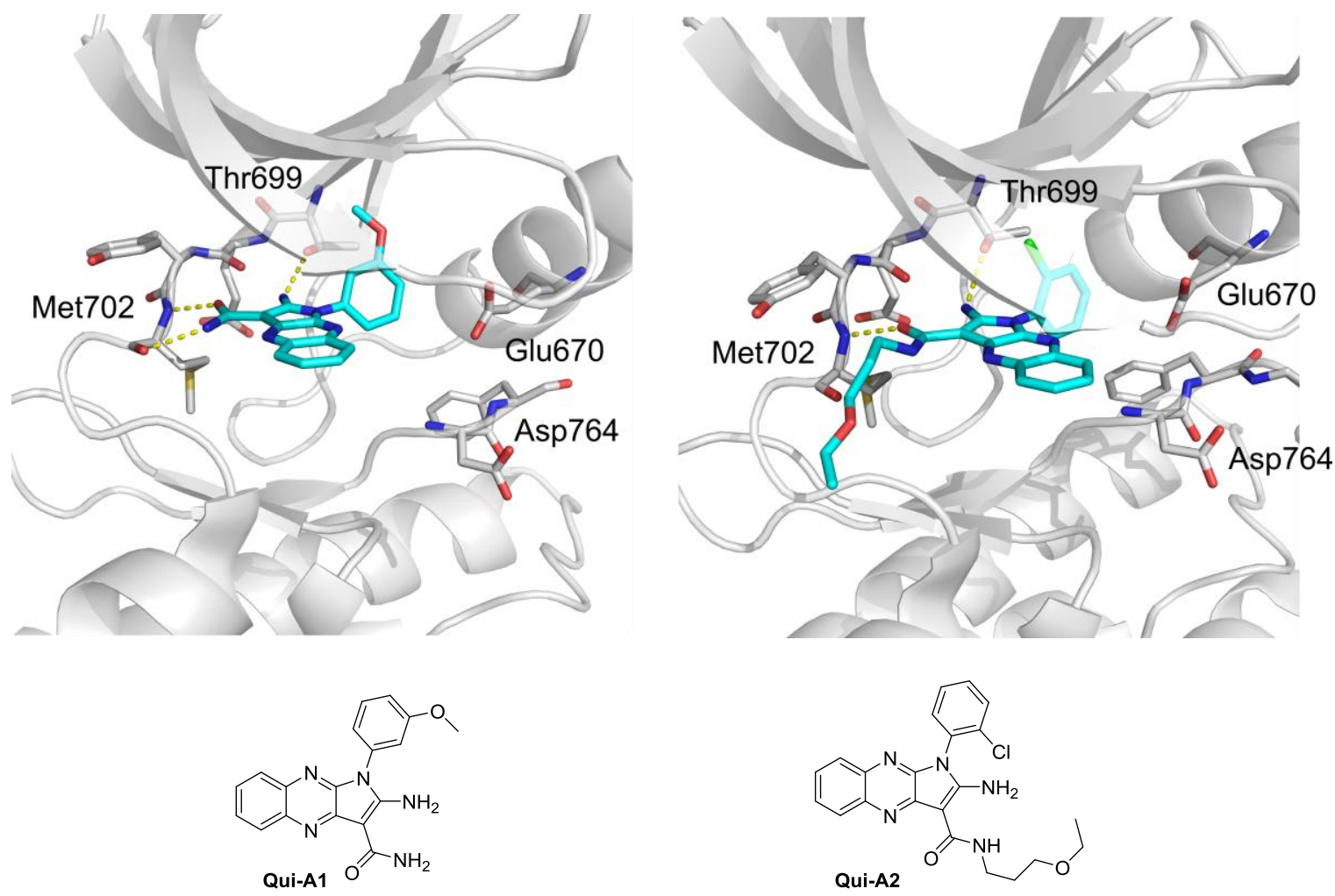

Figure 11. Crystal structures of the catalytic domain of the tyrosine kinase EphA3 in its DFG-in conformation in complex with the high-nanomolar inhibitors Qui-A1 (left, PDB code 4P4C) and Qui-A2 (right, PDB code 4P5Q). The ATP binding site of the EphA3 kinase and the inhibitors are shown as sticks.

The pyrrolo[3,2-b]quinoxaline scaffold binds within the ATP binding site with the phenyl substituent nestled into the so-called hydrophobic pocket. The amide substituent at position 3 of the pyrrole ring in Qui-A1 is able to form a total of two hydrogen bonds with Met696(702), a residue of the hinge region, whereas inhibitor Qui-A2, bearing an ethoxy substituted amide in trans configuration, establishes only one hydrogen bond with Met696(702). The amino substituent at position 2 of the pyrrole ring, present in both inhibitors, is involved in a bifurcated hydrogen bond with the hydroxyl side chain of the Thr693(699) gatekeeper and the backbone carbonyl of Glu694(700). The lack of a hydrogen bond in compound Qui-A2, together with the different substituents of the phenyl ring in the hydrophobic pocket, i.e., $\mathrm{OCH}_{3}$ and -Cl in Qui-A1 and Qui-A2, respectively, could explain the 10-fold weaker affinity of inhibitor Qui-A2 with respect to Qui-A1 (IC $\mathrm{C}_{50}$ of $300 \mathrm{nM}$ for EphB4). ${ }^{54}$

Given our acquired experience during the medicinal chemistry campaigns of the xanthine (Xan-A1-A3) $)^{55-56}$ and pyrimidine (Pyr-A1) ${ }^{50}$ scaffolds as well as earlier reports towards the synthesis of potent type I and type $\mathrm{I}_{1 / 2}$ kinase inhibitors, ${ }^{39}$ several modifications within the phenyl substituent of the quinoxaline scaffold were designed in order to fine tune the interactions of these type I inhibitors with the threonine gatekeeper residue, Thr693(699), as well as with the conserved glutamic acid residue, Glu664(670), and the activation loop, Asp758(764), in order to achieve type $\mathrm{I}_{1 / 2}$ and II inhibitors.

To modulate several properties of the hit compounds Qui-A1 and Qui-A2 such as potency, type of binding (type I, $\mathrm{I}_{1 / 2}$ and II) and drug-like properties, a convergent synthesis towards the quinoxaline scaffold was established (Scheme 3). Compound 7 was prepared 
according to previously reported procedures by condensation of commercially available 2,3dichloroquinoxaline with malononitrile in the presence of sodium hydride. ${ }^{68-69}$ The substitution of the chlorine at position 3 with commercially available or synthetically prepared anilines followed by cyclization afforded intermediates $8 .^{70}$ Hydrolysis of the cyano group under strong acidic conditions furnished the desired type I (Qui-A), I/2 (Qui-B) and type II (Qui-C) inhibitors.

\section{Scheme $3^{a}$}
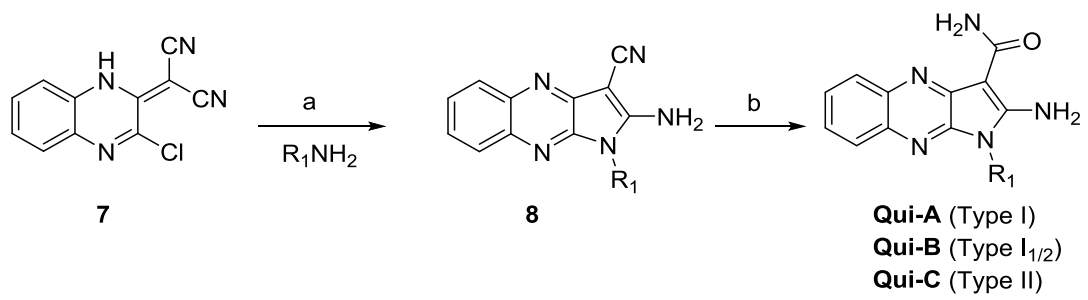

${ }^{a}$ Reagents and reaction conditions: a) Protocol I: $\mathrm{R}_{1} \mathrm{NH}_{2}$ (1-4 eq.), EtOH:Toluene, 1:1, 130-160 ${ }^{\circ} \mathrm{C}, 4-12$ h, 30-79\%. Protocol II: $\mathrm{R}_{1} \mathrm{NH}_{2}$ (1-1.2 eq.), DMF, $80^{\circ} \mathrm{C}, 12 \mathrm{~h}, 21-61 \%$. b) $\mathrm{H}_{2} \mathrm{SO}_{4}, 25^{\circ} \mathrm{C}, 30 \mathrm{~min}, 7-99 \%$.

Due to the rather limited space around the phenyl group revealed by the binding modes of Qui-A1 and Qui-A2, the introduction of small substituents was envisioned, including the incorporation of a methyl and a hydroxyl group at positions 2 and 5 , a combination that had been successfully exploited in our previous studies (Tables 3 and 4). ${ }^{50,55}$ The synthesized compounds were characterized by several biophysical techniques including fluorescence resonance energy transfer (FRET), EphB4 overexpressing cell based assays and differential scanning fluorimetry (also referred to as thermal shift). Differential scanning fluorimetry is a high throughput technique where the increase in thermal stability of a folded protein upon ligand binding is detected by a fluorescence dye while measuring its melting temperature during denaturation. ${ }^{71}$ 
Table 6. EphA3/EphB4 inhibition data for the synthesized quinoxaline type I and type $I_{1 / 2}$ derivatives

\begin{tabular}{|c|c|c|c|c|c|c|c|c|}
\hline Compound & $\begin{array}{l}\text { Type of } \\
\text { binding } \\
\end{array}$ & $\mathrm{R}_{1}$ & $\mathrm{R}_{2}$ & $\mathrm{R}_{3}$ & $\mathrm{R}_{4}$ & $\begin{array}{c}\text { Thermal shift } \\
\text { (degrees) }^{\mathrm{a}}\end{array}$ & $\begin{array}{c}\text { FRET }^{\mathrm{b}} \text { enzymatic } \\
\text { assay }(\%)\end{array}$ & $\begin{array}{c}\text { Cellular } \mathrm{IC}_{50} \\
(\mathrm{nM})^{\mathrm{C}}\end{array}$ \\
\hline Qui-A3 & I & $\mathrm{Me}$ & $\mathrm{H}$ & $\mathrm{H}$ & $\mathrm{H}$ & 4.1 & 66 & 230 \\
\hline $\begin{array}{l}\text { Qui-A4 } \\
\text { Qui-A5 } \\
\text { Qui-A6 } \\
\text { Qui-A7 } \\
\text { Qui-A8 } \\
\text { Qui-B1 } \\
\text { Qui-B2 }\end{array}$ & $\begin{array}{c}1 \\
1 \\
1 \\
1 \\
1 \\
I_{1 / 2} \\
I_{1 / 2}\end{array}$ & $\begin{array}{c}\mathrm{Me} \\
\mathrm{Me} \\
\mathrm{Me} \\
\mathrm{Cl} \\
\mathrm{F} \\
\mathrm{Me} \\
\mathrm{H}\end{array}$ & $\begin{array}{l}\mathrm{H} \\
\mathrm{H} \\
\mathrm{H} \\
\mathrm{H} \\
\mathrm{H} \\
\mathrm{H} \\
\mathrm{H}\end{array}$ & $\begin{array}{c}\mathrm{H} \\
\mathrm{H} \\
\mathrm{OMe} \\
\mathrm{H} \\
\mathrm{H} \\
\mathrm{CH}_{2} \mathrm{OH} \\
\mathrm{OH}\end{array}$ & $\begin{array}{c}\mathrm{Me} \\
\mathrm{Cl} \\
\mathrm{H} \\
\mathrm{H} \\
\mathrm{H} \\
\mathrm{H} \\
\mathrm{H}\end{array}$ & $\begin{array}{l}2.6 \\
2.6 \\
1.5 \\
3.0 \\
2.7 \\
3.6 \\
7.2\end{array}$ & $\begin{array}{l}36 \\
45 \\
23 \\
90 \\
30 \\
68 \\
98\end{array}$ & $\begin{array}{c}4400 \\
2800 \\
720 \\
\text { n. d. } \\
\text { n. d. } \\
160 \\
\text { n. d. }\end{array}$ \\
\hline Qui-B3 & $I_{1 / 2}$ & $\mathrm{H}$ & $\mathrm{H}$ & $\pi_{3-n}^{n-n}$ & $\mathrm{H}$ & 0.1 & 7 & n. d. \\
\hline Qui-B4 & $\mathrm{I}_{1 / 2}$ & $\mathrm{Me}$ & $\mathrm{H}$ & $\mathrm{OH}$ & $\mathrm{H}$ & 11.2 & 105 & 5.4 \\
\hline
\end{tabular}

The best inhibition values in type I inhibitors (ca. $4{ }^{\circ} \mathrm{C}$ in the thermal shift assay and 66 $\%$ inhibition in the FRET assay) were obtained for ortho-methyl (Qui-A3) and ortho-chlorine (Qui-A7) substituted quinoxalines, in line with previously reported kinase inhibitors (including Xan-A15, Table 1). ${ }^{37,55,58,72-75}$ However, the ortho-fluoro substituted inhibitor (Qui-A8) or bisortho substituted (Qui-A4 and Qui-A5) caused a lower stabilization of the protein as well as lower inhibition values in the FRET enzymatic assay probably due to the small size of fluorine or the introduction of an extra steric bulk, respectively. We were pleased to see that cellular phosphorylation assays on MEF cells transfected with myc-tagged human EphB4 revealed comparable inhibition values to the ones observed in the enzymatic assay (Table 6, column 9), with the ortho methyl substituted derivative Qui-A3 as the most potent member of this type I series $\left(\mathrm{IC}_{50}=230 \mathrm{nM}\right.$ in cells $)$.

The transition from type I to type $I_{1 / 2}$ inhibitors was accomplished by the introduction of a hydroxyl (Qui-B1, B2, B4) or triazole group (Qui-B3) at $\mathrm{R}_{3}$ that could establish hydrogen bonds with Glu664(670) and Asp758(764). These modifications resulted in a remarkable increase in potency for compound Qui-B2 $\left(7.2^{\circ} \mathrm{C}\right.$ in thermal shift and an inhibition of $98 \%$ in the FRET assay), which became more pronounced upon introduction of a methyl group in the ortho- relative position (following the trend observed in type I inhibitors, Table 6) to yield Qui-B4 with a thermal shift of $11.2^{\circ} \mathrm{C}$ and an $\mathrm{IC}_{50}$ value in EphB4 overexpressing cells of 5.4 $\mathrm{nM}$ (Table 6). To our surprise, a triazole group at the same position (Qui-B3) dramatically decreased the binding affinity (7\% inhibition).

The binding modes of the hit inhibitors Qui-A1 and Qui-A2 suggested the possibility of extending the quinoxaline scaffold into the allosteric binding site (generated by a DFG-out conformation of the kinase) by substitution of the phenyl ring, so that type II inhibitors could be achieved (Figure 11). The extra interactions formed in the DFG-out pocket and the lower sequence conservation of the inactive kinase conformation among different kinase families provide type II inhibitors a higher degree of selectivity. ${ }^{76-77}$ In order to target the back pocket 
of the kinase, a variety of substituents, some of which are present in known type II inhibitors, were envisioned. The so-called "tail" moiety of type II inhibitors, located within the allosteric binding site, is characterized by a hydrogen bond donor-acceptor pair (usually an amide or an urea), linked to a hydrophobic substituent that occupies the newly formed pocket in the DFG out conformation of the kinase..$^{2,78-79}$

Amide, urea and thiourea linkers were incorporated onto the quinoxaline scaffold and attached to a $m-\mathrm{CF}_{3}$-phenyl moiety present in AAL993, ${ }^{80}$ sorafenib, ${ }^{81-82}$ and GNF-5837 ${ }^{83}$ (Qui-C2-C4, Qui-C7-C9, Qui-C12, Qui-C13, Qui-C14, Table 7). These inhibitors caused a similar stabilization effect in the protein according to thermal shift as the type $I_{1 / 2}$ inhibitor Qui-B4 (Table 6). As already seen in previous results with type I and $I_{1 / 2}$ compounds (Table 6), the addition of a methyl (Qui-C3, Qui-C8) or fluorine (Qui-C4, Qui-C9) substituent in $\mathrm{R}_{1}$ lead to higher thermal shifts as well as slightly more potent $I_{50}$ values in cells overexpressing EphB4. Interestingly, 3-amides (Qui-C7-C10) triggered a higher stabilization of the kinase in the thermal shift assay than 1-amides (Qui-C2-C5), which could indicate the formation of a more favorable hydrogen bond with Glu664(670).

In an effort to increase the hydrophobic interactions within the allosteric binding site, 4methyl imidazole was added to mimic the well-known drug nilotinib ${ }^{84}$ (Qui-C5, Qui-C10). This approach generated compounds with the the most promising thermal shifts (ca. $16^{\circ} \mathrm{C}$ ), but such activity was not correlated with the cell based assays $\left(\mathrm{IC}_{50}\right.$ values of 170 and $\left.270 \mathrm{nM}\right)$, suggesting membrane permeability or efflux issues. Unfortunately, the addition of a cyclopropyl ring as substituent of the amide linker (Qui-C1, Qui-C6, Qui-C11), a common motif in p38 $\alpha$ isoform selective kinase inhibitors, ${ }^{85-87}$ resulted in no thermal shift.

Urea (Qui-C13) or thiourea (Qui-C14) linkers located in para- relative position of the phenyl ring retained or even enhanced (in the case of urea Qui-C13) the binding affinity, whereas compound Qui-C12, bearing the urea in meta- relative position barely presented any thermal shift, suggesting a disruption or a non-favorable hydrogen bond interactions with Glu664(670) and the activation loop in the DFG-out conformation. 
Table 7. EphA3/EphB4 inhibition data for the synthesized type II quinoxaline derivatives

\begin{tabular}{|c|c|c|c|c|c|}
\hline Compound & $\mathrm{R}_{1}$ & $\mathrm{R}_{2}$ & $\mathrm{R}_{3}$ & $\begin{array}{c}\text { Thermal shift } \\
\text { (degrees) }^{\mathrm{a}}\end{array}$ & $\begin{array}{c}\text { Cellular IC }{ }^{\text {InM) }} \\
\text { (nM) }\end{array}$ \\
\hline Qui-C1 & $\mathrm{H}$ & $\mathrm{H}$ & & 0.3 & n. d. \\
\hline Qui-C2 & $\mathrm{H}$ & $\mathrm{H}$ & & 7.6 & 20 \\
\hline Qui-C3 & $\mathrm{Me}$ & $\mathrm{H}$ & & 12.3 & 14 \\
\hline Qui-C4 & $F$ & $\mathrm{H}$ & & 10.9 & 15 \\
\hline Qui-C5 & $\mathrm{Me}$ & $\mathrm{H}$ & & 15.8 & 170 \\
\hline Qui-C6 & $\mathrm{H}$ & $\mathrm{H}$ & & 0.6 & n. d. \\
\hline Qui-C7 & $\mathrm{H}$ & $\mathrm{H}$ & & 9.1 & 20 \\
\hline Qui-C8 & $\mathrm{Me}$ & $\mathrm{H}$ & & 14.4 & 21 \\
\hline Qui-C9 & $F$ & $\mathrm{H}$ & & 13.0 & 24 \\
\hline Qui-C10 & $\mathrm{Me}$ & $\mathrm{H}$ & & 16.2 & 270 \\
\hline Qui-C11 & $\mathrm{H}$ & $\mathrm{H}$ & & 0.3 & n. d. \\
\hline Qui-C12 & $\mathrm{H}$ & $\mathrm{H}$ & & 0.7 & n. d. \\
\hline
\end{tabular}

$\begin{array}{llllll}\text { Qui-C13 } & \mathrm{H} & \mathrm{H} & 14.3 & 89 \\ \text { Qui-C14 } & \mathrm{H} & \mathrm{H} & 9.9 & 560\end{array}$

${ }^{a}$ Change in the melting temperature of EphA3 in the presence of the compound at a concentration of $20 \mu \mathrm{M}$. Average values of triplicate measurements. The standard deviation is smaller than 0.5 degrees. ${ }^{b}$ Cell $\mathrm{C}_{50}$ values were measured in a cellular phosphorylation assay using MEF cells overexpressing EphB4 at Proqinase. n. d.: not determined. The highlighted entries represent the most potent compounds.

\subsection{Study of binding kinetics}

The kinetics of binding of the optimized type $\mathrm{I}_{1 / 2}$ (Qui-B4) and type II urea inhibitor QuiC13 were investigated using surface plasmon resonance, where the change in refractive index on a chip coated with the protein of interest is measured upon ligand binding (Figure 12). Dissociation constants $\left(K_{D}\right)$ in the low nanomolar range were obtained for both, Qui-B4 and Qui-C13 (8.6 nM and $39.3 \mathrm{nM}$ respectively) upon titrating the inhibitors over immobilized dephosphorylated EphA3.

One of the advantageous characteristics of type II inhibitors over type I or $\mathrm{I}_{1 / 2}$ is their slow dissociation rate from the target protein, ${ }^{88-90}$ which is considered to be beneficial for drug efficacy and selectivity in vivo due to the high concentration of the drug near the 
target, ${ }^{90-91}$ as described for the EGFR-specific inhibitor lapatinib. ${ }^{92}$ The remarkably slow $\mathrm{k}_{\text {off }}$ measured for Qui-C13 $\left(1.45 \times 10^{-4} \mathrm{~s}^{-1}\right)$ denotes its type II binding mode. This value corresponds to a residence time of $115 \mathrm{~min}$, a value that compares positively with that of marketed drugs such as imatinib (28 min for dephosphorylated ABL), nilotinib (202 min and 205 min for dephosphorylated and phosphorylated ABL, respectively), and dasatinib (15 min and $4 \mathrm{~min}) .{ }^{93}$ The type $\mathrm{I}_{1 / 2}$ inhibitor Qui-B4, on the other hand, presents a faster $\mathrm{k}_{\text {off }}$ in comparison with the mentioned type II inhibitor Qui-C13 $\left(1.52 \times 10^{-3} \mathrm{~s}^{-1}\right)$.
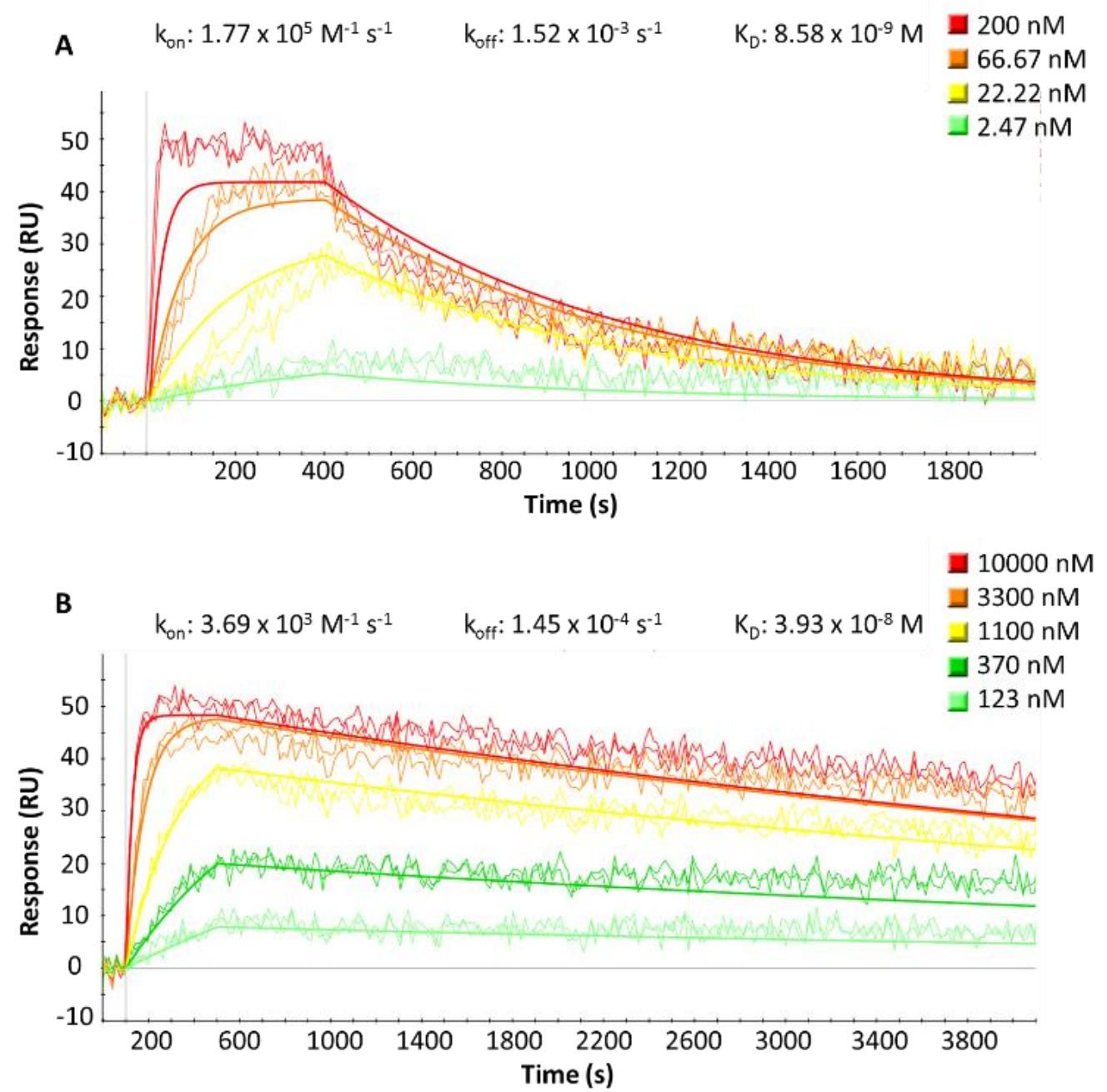

Figure 12. Surface plasmon resonance analysis of the binding of Qui-B4 (A) and QuiC13 (B) to EphA3. A threefold serial dilution of the compounds was made starting from 200 $\mathrm{nM}$ (for Qui-B4) and $10 \mu \mathrm{M}$ (for Qui-C13) in duplicate. The theoretical global fit to a $1: 1$ interaction model is shown in straight lines. Reprinted with permission from Unzue et al. J. Med. Chem. 2014, 57, 6834-6844. ${ }^{57}$

\subsection{Validation of type II binding by X-ray crystal structure determination}

The crystal structure of the catalytic domain of the EphA3 kinase in complex with inhibitor Qui-C13 was solved at 2.0 A resolution, confirming its type II binding mode, i.e., with the DFG-out conformation of the kinase (Figure 13). The pyrrolo[3,2-b]quinoxaline core occupies the ATP binding site, where it establishes two hydrogen bonds as the type I 
inhibitors (Figure 11). In addition, the urea linker of inhibitor Qui-C13 acts as hydrogen bond acceptor for the Ser757(763) side chain and the amide backbone of Asp758(764), and as hydrogen bond donor to the side chain of Glu664(670). The $m-\mathrm{CF}_{3}$-phenyl moiety is nestled in the newly formed hydrophobic pocket, which originates from the displacement of the Phe side chain of the DFG motif in the activation loop.
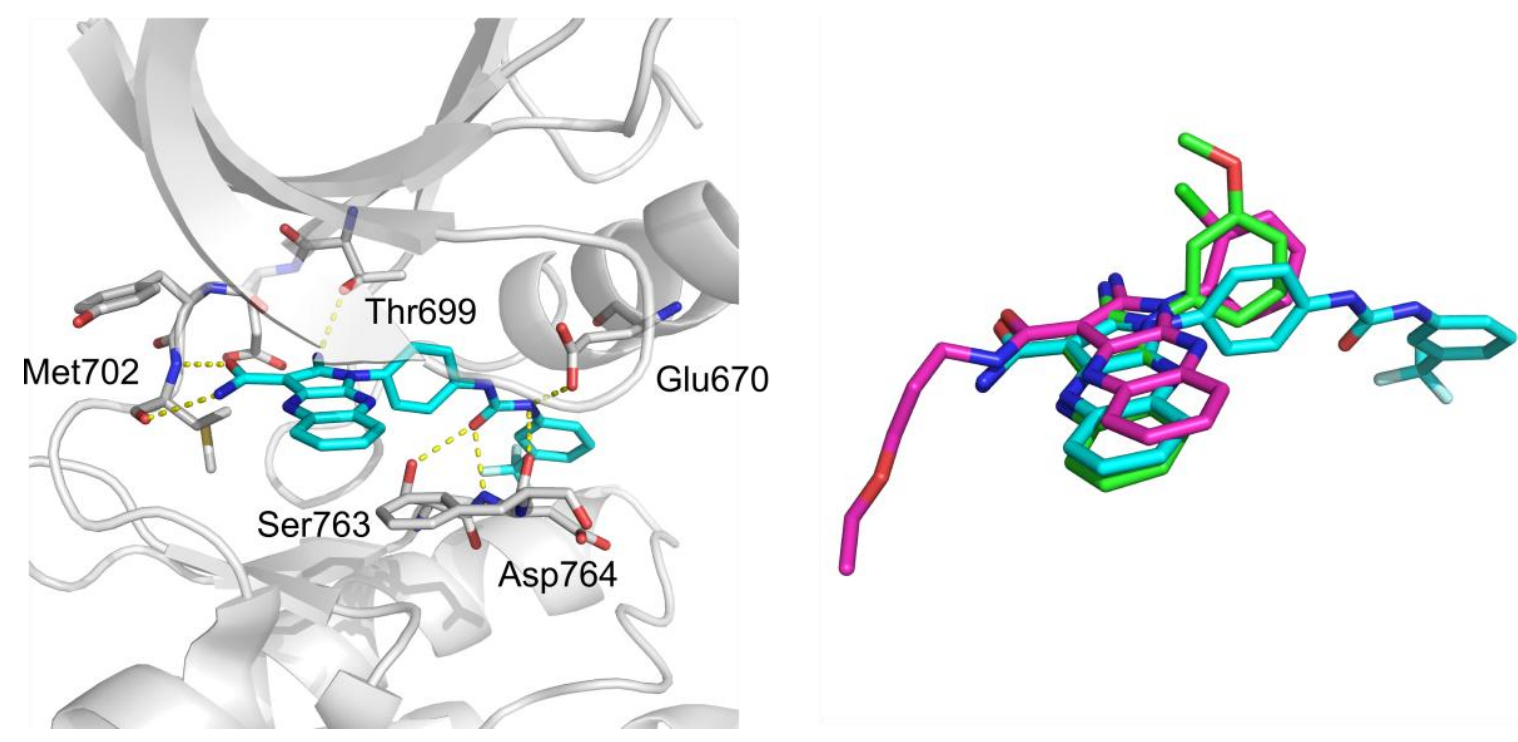

Figure 13. Crystal structures of the catalytic domain of the tyrosine kinase EphA3 in its DFG-out conformation in complex with the low-nanomolar inhibitor Qui-C13 (left, PDB code 4P5Z) and superposition of the three inhibitors Qui-A1, Qui-A2, and Qui-C13 based on structural alignment of the $\mathrm{C}_{\alpha}$ atoms of the EphA3 kinase domain (right). The ATP binding site of the EphA3 kinase and the side chains mentioned in the text and the inhibitors are shown as sticks.

\subsection{Selectivity profile}

The selectivity profile of inhibitors Qui-B4, Qui-C2 and Qui-C7 was determined by an in vitro competition binding assay ${ }^{67}$ against 453 recombinant kinases, 58 of which were disease related mutant kinases, mainly of $A B L 1, E G F R$, and PIK3CA.

Compounds Qui-B4, Qui-C2 and Qui-C7 present a very similar selectivity profile (Figure 14); in particular, strong binding is only observed to tyrosine kinases with threonine as a gatekeeper residue, suggesting that most (or even all) tyrosine kinases with a Thr gatekeeper can assume a DFG-out conformation. Interestingly, the selectivity profiles of the type $I_{1 / 2}$ (Qui-B4) and II (Qui-C2 and Qui-C7) quinoxaline-based inhibitors are very similar to our previously optimized type $I$ and $I_{1 / 2}$ xanthine-based inhibitors (Xan-A19 and Xan-B9, Figure 4$)^{55-56}$ and the pyrimidoisoquinolinone inhibitor Pyr-B1 (Figure 9), due, at least in part, to the use of an Eph tyrosine kinase (EphB4) as primary target for the in silico screening and optimization. Moreover, the tested quinoxaline derivatives show remarkable inhibition towards several mutant kinases (Figure 14, bottom). 


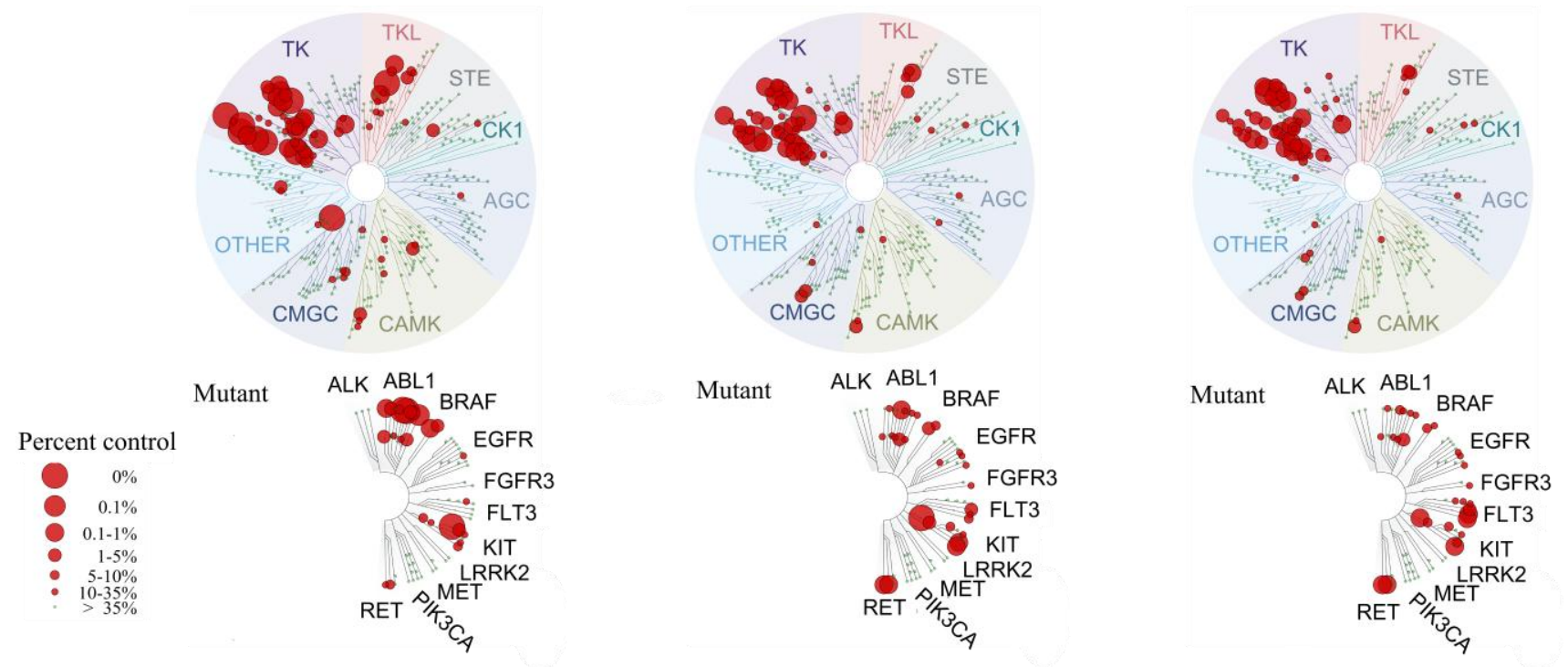

Figure 14. Selectivity profiles of compound Qui-B4 (left), Qui-C2 (center) and Qui-C7 (right) tested on a panel of 453 protein kinases at DiscoveRx. Measurements were performed at a $1 \mu \mathrm{M}$ concentration of the inhibitor. The affinity is defined with respect to a DMSO control. The dendrogram was obtained from KinomeScan using the KinomeTree software.

\subsection{Antiproliferative activity}

Compounds Qui-B4 and Qui-C13 were screened against the NCl-60 cancer cell line panel (Figure 15). Both compounds display high antiproliferative activities against leukemia (K-562), lung (HOP-92), colon (HT-29), renal (A498) and breast cancer cells (MDA-MB-231, HS 578T) in the low $\mathrm{nM}$ range, which constitutes a substantial improvement compared to our previous inhibitor series (Figure 5, compound Xan-B9). Interestingly, the inhibition pattern of Qui-B4 resembles that of dasatinib, while showing an overall less toxicity.

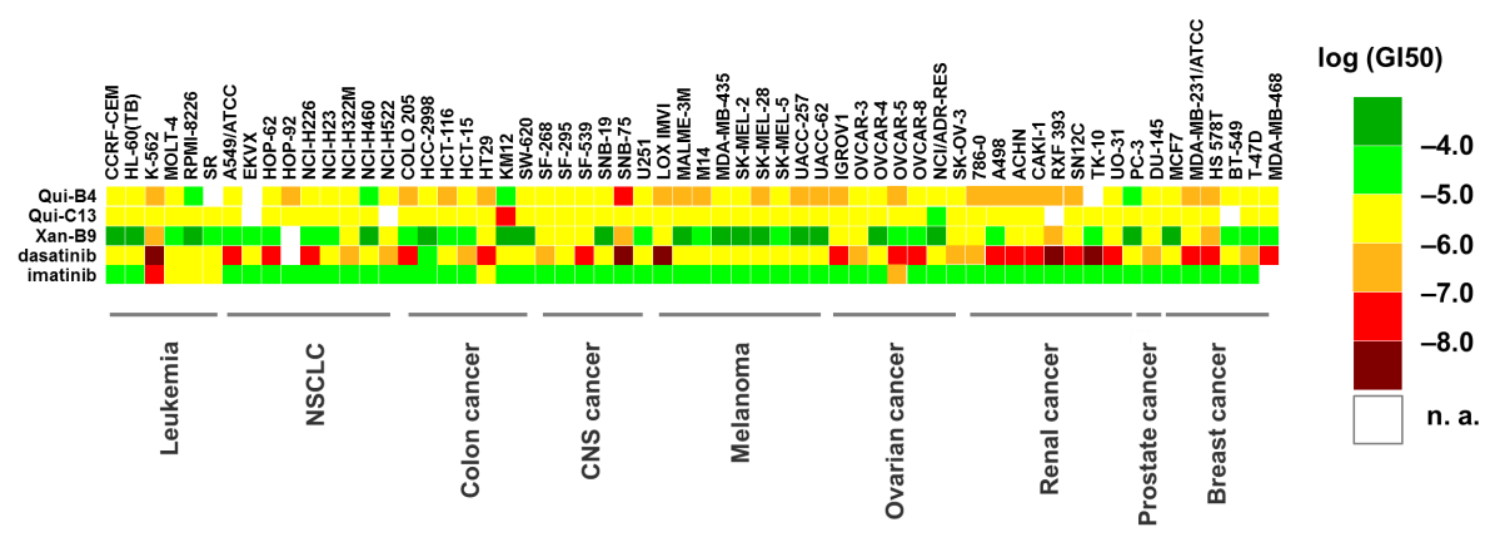

Figure 15. The antiproliferative activity of quinoxalines Qui-B4 and Qui-C13 is shown together with the growth inhibition of two anticancer drugs (dasatinib and imatinib) and our previous xanthine inhibitor Xan-B9. The growth inhibition is shown as a matrix with cell lines and compounds arranged vertically and horizontally, respectively. The legend bar shows the color coding which reflects the $\log \left(\mathrm{GI}_{50}\right)$ value, with red and green indicating high and low cytotoxicity, respectively. 
Based on these results, the most potent inhibitors of this optimization campaign were tested in-house against the above mentioned $\mathrm{NCl}$ cancer cell lines (Figure 16). The type II compounds could remarkably inhibit the proliferation of the leukemia cell line K-562, especially the 3-amide compounds Qui-C8 and Qui-C9, with $\mathrm{Gl}_{50}$ values of 36 and $81 \mathrm{nM}$ respectively. Interestingly, similar levels of potency were found for imidazole substituted compounds Qui-C5 and Qui-C10, which seemed to be among the weakest type II binders in the cellular phosphorylation assays (Table 7), possibly indicating the presence of other targets than Eph for these molecules. All in all, the mentioned type II inhibitors present nanomolar inhibition values in the K-562 cell line that compare positively to that of dasatinib and imatinib, making them very useful tools for the development of clinical candidates.

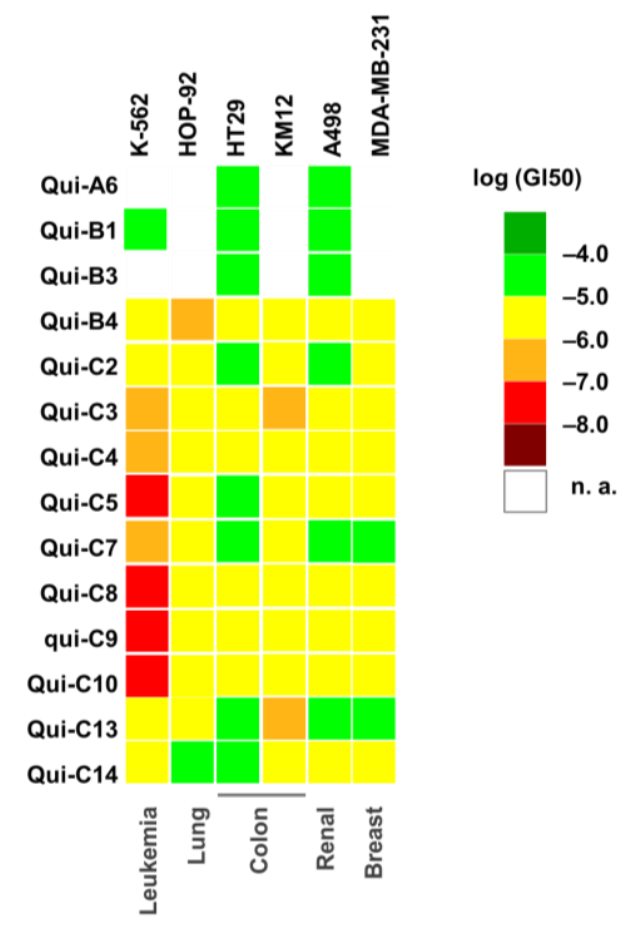

Figure 16. Antiproliferative activity against $\mathrm{NCl}$ tumor cell lines. $\mathrm{GI}_{50}$ values were determined using resazurin reduction after 2-3 days of incubation with the corresponding compound. The growth inhibition is shown as the mean of at least three independent experiments as a matrix with cell lines and compounds arranged vertically and horizontally, respectively.

In addition, the antiproliferative activity of Qui-B4 (the most potent compound on cellular phosphorylation assays with an $\mathrm{IC}_{50}$ of $5.4 \mathrm{nM}$ ) in patient-derived tumor cell lines (including colon, lung, kidney, pancreatic, prostate, and stomach cancer cells) was studied using a propidium iodide-based proliferation assay and dasatinib as a reference (Oncotest, Figure 17). Low micromolar $\mathrm{GI}_{50}$ values were obtained, $\mathrm{RXF} 393 \mathrm{NL}$ being the most sensitive cell line. 


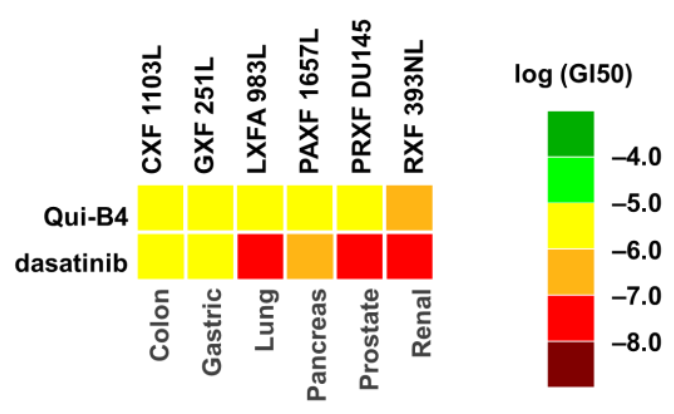

Figure 17. Anti-proliferative activity against patient-derived tumor cell lines. $\mathrm{GI}_{50}$ values were determined at Oncotest using a modified propidium iodide assay. Measurements were done after 4 days of incubation with the corresponding compound. The growth inhibition is shown as a matrix with cell lines and compounds arranged vertically and horizontally, respectively.

\subsection{Cellular angiogenesis assay}

The efficacy of Qui-B4 on human endothelial cell sprouting in a spheroid based cellular angiogenesis assay (ProQinase) was examined. ${ }^{94}$ Qui-B4 successfully inhibited VEGF-A induced HUVEC (primary human umbilical vein endothelial cells) sprouting in a dose dependent manner with an $\mathrm{IC}_{50}$ value of $1.5 \mu \mathrm{M}$. However, no significant effects on tube length, branching points and number of loops were observed an in vitro matrigel angiogenesis assay (Figure 18) for compounds Qui-B4, Qui-C7 and Qui-C13, in contrast to the previously developed xanthine inhibitors (Figure 7).
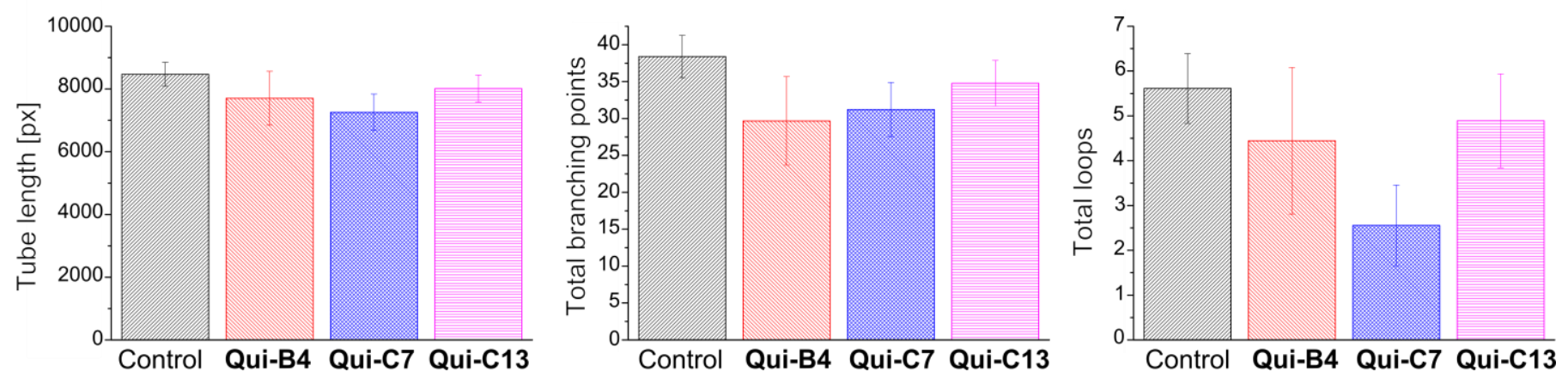

Figure 18. In vitro angiogenesis assay on tube formation. Compounds were incubated with HUEVEC cells seeded on matrigel for $15 \mathrm{~h}$. Tube length (left), total branching points (middle) and total loops were quantified. All measurements were done at least in triplicate, and their SEM values are indicated as error bars.

\subsection{Fluorescent properties of quinoxalines for cellular imaging}

The fluorescent properties of some of the type I and type $I_{1 / 2}$ Qui-derivatives were evaluated concluding that all compounds presented similar absorption ( $\left.\lambda_{\mathrm{abs}}=370 \mathrm{~nm}\right)$ and emission properties $\left(\lambda_{\mathrm{abs}}=430 \mathrm{~nm}\right)$, which makes them suitable for cellular imaging. In addition, their quantum yields were measured in acetonitrile, obtaining values between 0.20 and 0.25 , indicative of their remarkable fluorescence properties (Table 8). 
Table 8. Quantum yield measurements

\begin{tabular}{cc}
\hline Compound & $\begin{array}{c}\text { Quantum yield } \\
(\varphi)\end{array}$ \\
\hline Qui-A3 & 0.20 \\
Qui-A4 & 0.21 \\
Qui-A5 & 0.22 \\
Qui-A6 & 0.22 \\
Qui-B1 & 0.23 \\
Qui-B4 & 0.25 \\
\hline
\end{tabular}

This being the case, the most potent type $I_{1 / 2}$ inhibitor, Qui-B4, was incubated in the presence of the breast cancer cells MDA-MD-231 (for which a low micromolar $\mathrm{Gl}_{50}$ value was obtained, Figure 15). After two hours of incubation, significant changes in cell morphology were observed, including cell shrinkage and disruption of cell-cell adhesion (Figure 19 A, B). Such morphology changes resemble to the ones obtained with the CDK inhibitor roscovitine ${ }^{95}$ and have been shown to be associated with apoptosis.

In addition, fluorescence emission of compound Qui-B4 was detected within the cytoplasm of MDA-MB-231 cells after 2 hours of incubation, which confirms a remarkable cell membrane permeability, as well as fluorescence properties of this compound for in vitro imaging (Figure 19, C).
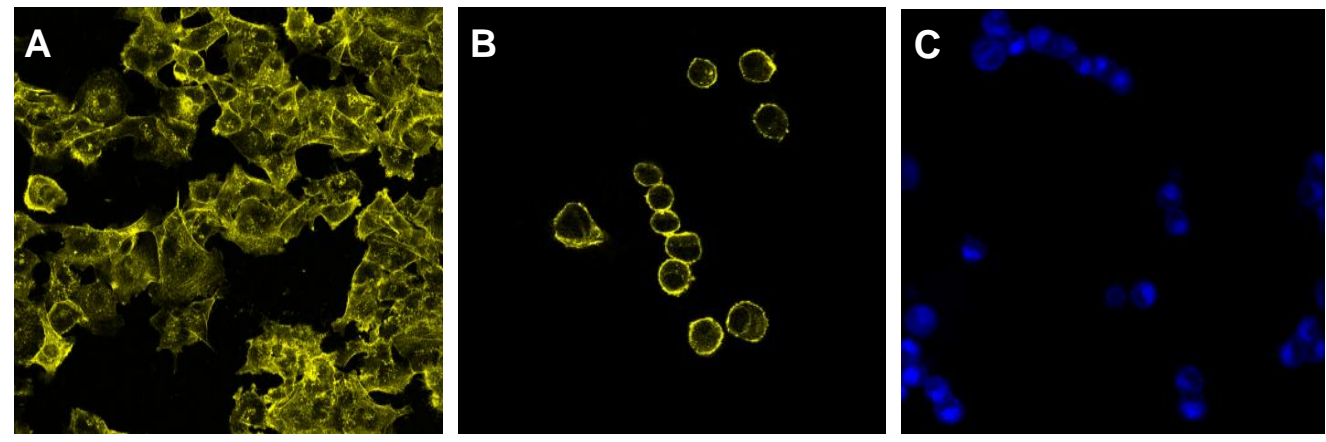

Figure 19. Fluorescence images of MDA-MB-231 cells. A) Control cells where the actin cytoskeleton is stained with tetramethylrhodamine isothiocyanate (TRITC)-phalloidin. B) Actin is stained after $2 \mathrm{~h}$ of incubation with compound Qui-B4 $(25 \mu \mathrm{M})$. C) Fluorescence of compound Qui-B4 $(25 \mu \mathrm{M})$ after $2 \mathrm{~h}$ incubation.

\subsection{In vivo studies}

Prior to the in vivo studies, we decided to address the metabolic stability of three of our most promising quinoxaline inhibitors (Qui-B4, Qui-C2 and Qui-C7, Supplementary Figure 4) using human liver microsomes. The results indicated half-lives longer than 60 minutes for the three compounds, data that compares positively to that of known drugs such as imipramine (half-life $>60 \mathrm{~min}$ ), propranolol (half-life $>60 \mathrm{~min}$ ), terfenadine (half-life $=15.5 \mathrm{~min}$ ) and verapamil (half-life $=32 \mathrm{~min}$ ) tested in a similar setting. 
Subsequently, the pharmacokinetic properties of these compounds were determined in 20-30 g male CD-1 (ICR) mice on intravenous (IV) and oral (PO) administration. The compounds presented low to moderate oral bioavailability, as well as high compound clearance $(\mathrm{Cl})$ and moderate half-life $\left(\mathrm{T}_{1 / 2}\right)$ values, with compounds Qui-C2 and Qui-C7 showing the most promising values (Table 9).

Good cellular efficacy and pharmacokinetic properties triggered the subsequent evaluation of compound Qui-B4 in a xenograft mouse model with a tumor derived from the MDA-MB-231 cell line in a twice-daily dosing regime totaling $100 \mathrm{mg} / \mathrm{kg} / \mathrm{day}$ of compound Qui-B4 over 21 days. Median tumor volume progression over time, starting from $108 \mathrm{~mm}^{3}$, of both treatment and control cohorts is given in Figure 20.

Table 9. Pharmacokinetic properties in mice

\begin{tabular}{lllllll}
\hline \multirow{2}{*}{ Compound } & \multicolumn{2}{c}{ Qui-B4 } & \multicolumn{2}{c}{ Qui-C2 } & \multicolumn{2}{c}{ Qui-C7 } \\
& IV & PO & IV & PO & IV & PO \\
\hline Dose $(\mathrm{mg} / \mathrm{kg})$ & 1 & 5 & 1 & 5 & 1 & 5 \\
Cl $(\mathrm{mL} / \mathrm{min} / \mathrm{kg})$ & 42 & - & 32 & - & 31 & - \\
$\mathrm{V}_{\mathrm{ss}}(\mathrm{L} / \mathrm{kg})$ & 1.6 & - & 2.2 & - & 2.2 & - \\
$\mathrm{T}_{1 / 2}(\mathrm{~h})$ & 1.7 & 1.7 & 1.2 & 5.0 & 1.1 & 2.8 \\
AUClast & 392 & 493 & 506 & 263 & 533 & 803 \\
(h.ng/mL) & - & 25 & - & 10 & - & 30 \\
$\mathrm{~F}(\%)$ & & & & & & \\
\hline
\end{tabular}

Remarkably compound Qui-B4 inhibited tumor growth by $80 \%$ in comparison to the control mice. Thus Qui-B4 is a potent cytostatic agent as the tumor volume remained almost constant throughout the nearly three weeks of the study. Mean body weight of the treatment cohort decreased up to $16 \%$ of the initial mean body weight during the treatment period. These promising results suggest that further studies of such xenograft model at lower doses of compound Qui-B4 might provide tumor volume control with lessened weight loss. Moreover, efficacy studies with type II quinoxaline inhibitors on mouse models of K-562 leukemia are currently undergoing. 


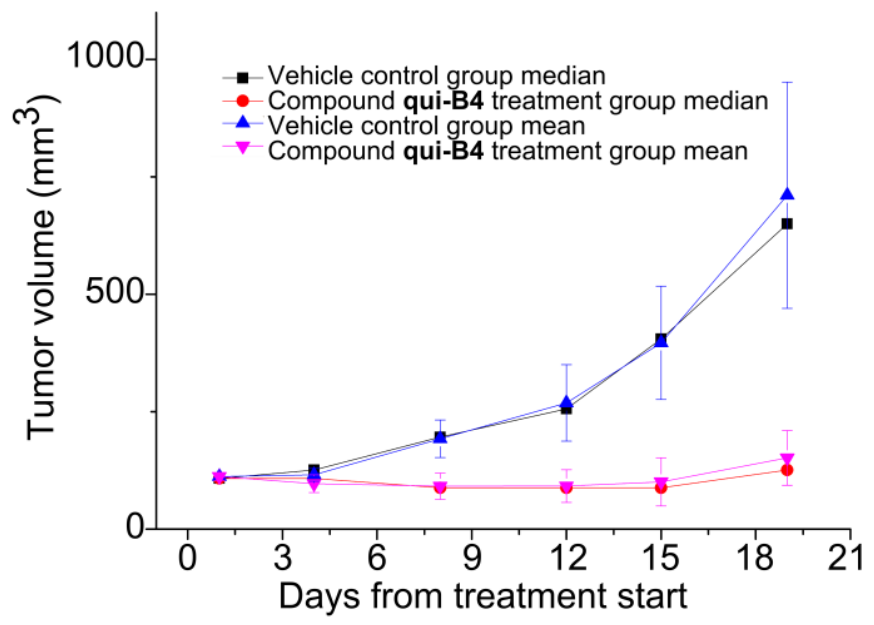

Figure 20. In vivo antitumor activity of compound Qui-B4 in MDA-MB-231 nude mice xenografts. The mice received by gavage twice-daily $50 \mathrm{mg} / \mathrm{kg}$ of compound Qui-B4 (red and pink) or vehicle control (black and blue). Each data point is the median or average of a cohort of 9 animals.

\section{Conclusions}

Seven different chemotypes of inhibitors of the catalytic domain of the Eph tyrosine kinases have been identified by methods developed in house for high-throughput docking and scoring. ${ }^{96}$ The combination of a fragment-based approach for docking and accurate evaluation of binding energy (including electrostatic desolvation upon binding) has resulted in a very high hit rate. ${ }^{97}$ With the support of the predicted binding mode and/or structural information obtained by protein crystallography, the hit optimization has required the synthesis of a relatively low number of derivatives: 34,1 , and 24 derivatives of the xanthine, pyrimidoisoquinolinone, and quinoxaline hits, respectively. Based on the X-ray structures of the initial hits of type I in complex with EphA3, the binding mode could be tuned into the type $\mathrm{I}_{1 / 2}$ and type II where the latter is characterized by the DFG-out orientation of the protein. The three optimization campaigns have culminated in several nanomolar Eph inhibitors with good selectivities and remarkable inhibition of proliferation of several tumor cell lines. Furthermore, the efficacy of our Eph kinase inhibitors on in vitro angiogenesis assays has also been validated.

The in depth medicinal chemistry optimization performed for the xanthine scaffold based on its predicted binding mode, resulted in the single digit nanomolar type $\mathrm{I}_{1 / 2}$ inhibitor Xan-B9. The efflux observed for this compound on Caco-2 monolayers was overcome by fine tuning the substituents of the xanthine core in a second optimization campaign, yielding Xan-A19 as nanomolar potent inhibitor with no efflux on cell based assays. In addition, both inhibitors, Xan-B9 and Xan-A19 proved to have a good selectivity profile on a 124 kinase panel. The efficacy of these inhibitors was assessed in an in vitro angiogenesis assay, which provided further evidence for the potential of this series for further development. The knowledge obtained during the optimization of the xanthine scaffold was then applied to optimize an in 
silico discovered pyrimidoisoquinolinone hit, whose affinity could be improved over 30 fold by the synthesis of a single derivative, Pyr-B1.

The third optimization campaign was carried out on a quinoxaline scaffold, for which the crystal structures of two type I hits were used to design type $I_{1 / 2}$ and type II inhibitors. Chemical synthesis of 24 derivatives led to several low nanomolar inhibitors with good selectivity profile. Importantly, the type II binding mode could be confirmed by solving the crystal structure of the complex of the EphA3 kinase and Qui-C13 which shows that the Phe side chain of the DFG-triad points in an out orientation. Moreover, the slow $\mathrm{k}_{\text {off }}$ determined by surface plasmon resonance provides additional evidence for the type II binding mode. Remarkable cell growth inhibition values obtained with the quinoxaline series led to the assessment of the efficacy of compound Qui-B4 in vivo (nude mice xenografted with human breast cancer). Qui-B4 showed strong cytostatic activity, confirming the importance of the quinoxaline derivative series for further preclinical development.

\section{Author information}

Corresponding Authors

*(C.N.) E-mail: cristina.nevado@chem.uzh.ch. Phone: (41)446353945. Fax: (41) 446353948.

*(A.C.) E-mail: caflisch@bioc.uzh.ch.

Author Contributions

A.U., K. L., and H. Z. contributed equally to this work.

\section{Acknowledgments}

We thank Dr. Danzhi Huang for interesting discussions and support in the initial phase of the Eph kinase project. We are thankful to Dr. Dimitrios Spiliotopoulos for help to compose the graphics plotting the antiproliferative activity data. This work was supported financially by the

Swiss National Science Foundation, the Swiss Cancer League (Krebsliga), and the Forschungskredit of the University of Zurich.

\section{Abbreviations}

Abl1, Abelson tyrosine-protein kinase 1; ALTA, Anchored-based Llibrary Tailoring; ATP, Adenosine triphosphate; CDK, Cyclin-dependent kinase; $\mathrm{Cl}$, clearance; DIPEA, $N, N$ Diisopropylethylamine; DMF, Dimethylformamide; EGFR, Epidermal growth factor receptor; Eph, erythropoietin-producing human hepatocellular carcinoma; FDA, Food and Drug Administration; FRET, Förster Resonance Energy Transfer; HUEVEC, Human Umbilical Vein Endothelial Cells; IV, intravenous; MD, Molecular Dynamics; MEF, murine embryonal fibroblast; MW, microwave; NCI, National Cancer Institute; PIK3CA, phosphatidylinositol-4,5bisphosphate 3-kinase catalytic subunit alpha; PO, per os, oral administration; QM, Quantum 
Mechanics; RTK, Receptor Tyrosine Kinases; SAR, Structure Activity Relationship; SEM, standard error of the mean; TRITC, Tetramethylrhodamine isothiocyanate; VEGF, Vascular Endothelial Growth Factor.

\section{References}

1. Manning, G.; Whyte, D. B.; Martinez, R.; Hunter, T.; Sudarsanam, S. The protein kinase complement of the human genome. Science 2002, 298, 1912-1934.

2. Zhang, J.; Yang, P. L.; Gray, N. S. Targeting cancer with small molecule kinase inhibitors. Nat. Rev. Cancer 2009, 9, 28-39.

3. Chico, L. K.; Van Eldik, L. J.; Watterson, D. M. Targeting protein kinases in central nervous system disorders. Nat. Rev. Drug Discov. 2009, 8, 892-909.

4. $\quad$ Cohen, P. Protein kinases--the major drug targets of the twenty-first century? Nat. Rev. Drug Discov. 2002, 1, 309-315.

5. Kumar, R.; Singh, V. P.; Baker, K. M. Kinase inhibitors for cardiovascular disease. J. Mol. Cell. Cardiol. 2007, 42, 1-11.

6. Doerig, C.; Billker, O.; Pratt, D.; Endicott, J. Protein kinases as targets for antimalarial intervention: Kinomics, structure-based design, transmission-blockade, and targeting host cell enzymes. BBA-Proteins Proteom. 2005, 1754, 132-150.

7. Schlessinger, J. Receptor Tyrosine Kinases: Legacy of the First Two Decades. Cold Spring Harb. Perspect. Biol. 2014, 6.

8. Pasquale, E. B. Eph-ephrin promiscuity is now crystal clear. Nat. Neurosci. 2004, 7, 417-418.

9. Himanen, J. P.; Nikolov, D. B. Eph receptors and ephrins. Int. J. Biochem. Cell Biol. 2003, 35, 130-134.

10. Gale, N. W.; Holland, S. J.; Valenzuela, D. M.; Flenniken, A.; Pan, L.; Ryan, T. E.; Henkemeyer, M.; Strebhardt, K.; Hirai, H.; Wilkinson, D. G.; Pawson, T.; Davis, S.; Yancopoulos, G. D. Eph receptors and ligands comprise two major specificity subclasses and are reciprocally compartmentalized during embryogenesis. Neuron 1996, 17, 9-19.

11. Kumar, S. R.; Singh, J.; Xia, G.; Krasnoperov, V.; Hassanieh, L.; Ley, E. J.; Scehnet, J.; Kumar, N. G.; Hawes, D.; Press, M. F.; Weaver, F. A.; Gill, P. S. Receptor tyrosine kinase EphB4 is a survival factor in breast cancer. Am. J. Pathol. 2006, 169, 279-293.

12. Xia, G. B.; Kumar, S. R.; Masood, R.; Zhu, S. T.; Reddy, R.; Krasnoperov, V.; Quinn, D. I.; Henshall, S. M.; Sutherland, R. L.; Pinski, J. K.; Daneshmand, S.; Buscarini, M.; Stein, J. P.; Zhong, C.; Broek, D.; Roy-Burman, P.; Gill, P. S. EphB4 expression and biological significance in prostate cancer. Cancer Res. 2005, 65, 4623-4632.

13. Stephenson, S. A.; Slomka, S.; Douglas, E. L.; Hewett, P. J.; Hardingham, J. E. Receptor protein tyrosine kinase EphB4 is up-regulated in colon cancer. BMC Mol. Biol. 2001, 2, 15.

14. Berclaz, G.; Karamitopoulou, E.; Mazzucchelli, L.; Rohrbach, V.; Dreher, E.; Ziemiecki, A.; Andres, A. C. Activation of the receptor protein tyrosine kinase EphB4 in endometrial hyperplasia and endometrial carcinoma. Ann. Oncol. 2003, 14, 220-226.

15. Huang, X.; Yamada, Y.; Kidoya, H.; Naito, H.; Nagahama, Y.; Kong, L.; Katoh, S. Y.; Li, W. F.; Ueno, M.; Takakura, N. EphB4 overexpression in B16 melanoma cells affects arterial-venous patterning in tumor angiogenesis. Cancer Res. 2007, 67, 9800-9808.

16. Castellano, G.; Reid, J. F.; Alberti, P.; Carcangiu, M. L.; Tomassetti, A.; Canevari, S. New potential ligand-receptor signaling loops in ovarian cancer identified in multiple gene expression studies. Cancer Res. 2006, 66, 10709-10719.

17. Xia, G. B.; Kumar, S. R.; Masood, R.; Koss, M.; Templeman, C.; Quinn, D.; Zhu, S. T.; Reddy, R.; Krasnoperov, V.; Gill, P. S. Up-regulation of EphB4 in mesothelioma and its biological significance. Clin. Cancer. Res. 2005, 11, 4305-4315.

18. Noren, N. K.; Lu, M.; Freeman, A. L.; Koolpe, M.; Pasquale, E. B. Interplay between EphB4 on tumor cells and vascular ephrin-B2 regulates tumor growth. Proc. Natl. Acad. Sci. U. S. A. 2004, $101,5583-5588$. 
19. Batlle, E.; Bacani, J.; Begthel, H.; Jonkeer, S.; Gregorieff, A.; van de Born, M.; Malats, N.; Sancho, E.; Boon, E.; Pawson, T.; Gallinger, S.; Pals, S.; Clevers, H. EphB receptor activity suppresses colorectal cancer progression. Nature 2005, 435, 1126-1130.

20. Noren, N. K.; Foos, G.; Hauser, C. A.; Pasquale, E. B. The EphB4 receptor suppresses breast cancer cell tumorigenicity through an Abl-Crk pathway. Nat. Cell Biol. 2006, 8, 815-U853.

21. Dopeso, H.; Mateo-Lozano, S.; Mazzolini, R.; Rodrigues, P.; Lagares-Tena, L.; Ceron, J.; Romero, J.; Esteves, M.; Landolfi, S.; Hernandez-Losa, J.; Castano, J.; Wilson, A. J.; Cajal, S. R. Y.; Mariadason, J. M.; Schwartz, S.; Arango, D. The Receptor Tyrosine Kinase EPHB4 Has Tumor Suppressor Activities in Intestinal Tumorigenesis. Cancer Res. 2009, 69, 7430-7438.

22. Kertesz, N.; Krasnoperov, V.; Reddy, R.; Leshanski, L.; Kumar, S. R.; Zozulya, S.; Gill, P. S. The soluble extracellular domain of EphB4 (sEphB4) antagonizes EphB4-EphrinB2 interaction, modulates angiogenesis, and inhibits tumor growth. Blood 2006, 107, 2330-2338.

23. Martiny-Baron, G.; Korff, T.; Schaffner, F.; Esser, N.; Eggstein, S.; Marme, D.; Augustin, H. G. Inhibition of tumor growth and angiogenesis by soluble EphB4. Neoplasia 2004, 6, 248-257.

24. Koolpe, M.; Burgess, R.; Dail, M.; Pasquale, E. B. EphB receptor-binding peptides identified by phage display enable design of an antagonist with ephrin-like affinity. J. Biol. Chem. 2005, 280, 17301-17311.

25. Chrencik, J. E.; Brooun, A.; Recht, M. I.; Kraus, M. L.; Koolpe, M.; Kolatkar, A. R.; Bruce, R. H.; Martiny-Baron, G.; Widmer, H.; Pasquale, E. B.; Kuhn, P. Structure and thermodynamic characterization of the EphB4/ephrin-B2 antagonist peptide complex reveals the determinants for receptor specificity. Structure 2006, 14, 321-330.

26. Incerti, M.; Tognolini, M.; Russo, S.; Pala, D.; Giorgio, C.; Hassan-Mohamed, I.; Noberini, R.; Pasquale, E. B.; Vicini, P.; Piersanti, S.; Rivara, S.; Barocelli, E.; Mor, M.; Lodola, A. Amino Acid Conjugates of Lithocholic Acid As Antagonists of the EphA2 Receptor. J. Med. Chem. 2013, 56, 2936-2947.

27. Duggineni, S.; Mitra, S.; Noberini, R.; Han, X. F.; Lin, N.; Xu, Y.; Tian, W.; An, J.; Pasquale, E. B.; Huang, Z. W. Design, synthesis and characterization of novel small molecular inhibitors of ephrin-B2 binding to EphB4. Biochem. Pharmacol. 2013, 85, 507-513.

28. Miyazaki, Y.; Nakano, M.; Sato, H.; Truesdale, A. T.; Stuart, J. D.; Nartey, E. N.; Hightower, K. E.; Kane-Carson, L. Design and effective synthesis of novel templates, 3,7-diphenyl-4amino-thieno and furo-[3,2-c]pyridines as protein kinase inhibitors and in vitro evaluation targeting angiogenetic kinases. Bioorg. Med. Chem. Lett. 2007, 17, 250-254.

29. Bardelle, C.; Cross, D.; Davenport, S.; Kettle, J. G.; Ko, E. J.; Leach, A. G.; Mortlock, A.; Read, J.; Roberts, N. J.; Robins, P.; Williams, E. J. Inhibitors of the tyrosine kinase EphB4. Part 1: Structure-based design and optimization of a series of 2,4-bis-anilinopyrimidines. Bioorg. Med. Chem. Lett. 2008, 18, 2776-2780.

30. Bardelle, C.; Coleman, T.; Cross, D.; Davenport, S.; Kettle, J. G.; Ko, E. J.; Leach, A. G.; Mortlock, A.; Read, J.; Roberts, N. J.; Robins, P.; Williams, E. J. Inhibitors of the tyrosine kinase EphB4. Part 2: Structure-based discovery and optimisation of 3,5-bis substituted anilinopyrimidines. Bioorg. Med. Chem. Lett. 2008, 18, 5717-5721.

31. Bardelle, C.; Barlaam, B.; Brooks, N.; Coleman, T.; Cross, D.; Ducray, R.; Green, I.; Lambertvan der Brempt, C.; Olivier, A.; Read, J. Inhibitors of the tyrosine kinase EphB4. Part 3: Identification of non-benzodioxole-based kinase inhibitors. Bioorg. Med. Chem. Lett. 2010, 20, 6242-6245.

32. Barlaam, B.; Ducray, R.; Lambert-van der Brempt, C.; Ple, P.; Bardelle, C.; Brooks, N.; Coleman, T.; Cross, D.; Kettle, J. G.; Read, J. Inhibitors of the tyrosine kinase EphB4. Part 4: Discovery and optimization of a benzylic alcohol series. Bioorg. Med. Chem. Lett. 2011, 21, $2207-$ 2211.

33. Mitchell, S. A.; Danca, M. D.; Blomgren, P. A.; Darrow, J. W.; Currie, K. S.; Kropf, J. E.; Lee, S. H.; Gallion, S. L.; Xiong, J. M.; Pippin, D. A.; DeSimone, R. W.; Brittelli, D. R.; Eustice, D. C.; Bourret, A.; Hill-Drzewi, M.; Maciejewski, P. M.; Elkin, L. L. Imidazo[1,2-a]pyrazine diaryl ureas: Inhibitors of the receptor tyrosine kinase EphB4. Bioorg. Med. Chem. Lett. 2009, 19, 69916995.

34. Choi, Y.; Syeda, F.; Walker, J. R.; Finerty, P. J.; Cuerrier, D.; Wojciechowski, A.; Liu, Q. S.; Dhe-Paganon, S.; Gray, N. S. Discovery and structural analysis of Eph receptor tyrosine kinase inhibitors. Bioorg. Med. Chem. Lett. 2009, 19, 4467-4470. 
35. Qiao, L. X.; Choi, S.; Case, A.; Gainer, T. G.; Seyb, K.; Glicksman, M. A.; Lo, D. C.; Stein, R. L.; Cuny, G. D. Structure-activity relationship study of EphB3 receptor tyrosine kinase inhibitors. Bioorg. Med. Chem. Lett. 2009, 19, 6122-6126.

36. Martiny-Baron, G.; Holzer, P.; Billy, E.; Schnell, C.; Brueggen, J.; Ferretti, M.; Schmiedeberg, N.; Wood, J. M.; Furet, P.; Imbach, P. The small molecule specific EphB4 kinase inhibitor NVPBHG712 inhibits VEGF driven angiogenesis. Angiogenesis 2010, 13, 259-267.

37. Wang, Y.; Shakespeare, W. C.; Huang, W. S.; Sundaramoorthi, R.; Lentini, S.; Das, S.; Liu, S.; Banda, G.; Wen, D.; Zhu, X.; Xu, Q.; Keats, J.; Wang, F.; Wardwell, S.; Ning, Y.; Snodgrass, J. T.; Broudy, M. I.; Russian, K.; Dalgarno, D.; Clackson, T.; Sawyer, T. K. Novel N9-arenethenyl purines as potent dual Src/Abl tyrosine kinase inhibitors. Bioorg. Med. Chem. Lett. 2008, 18, 4907-4912.

38. Stroylov, V. S.; Rakitina, T. V.; Novikov, F. N.; Stroganov, O. V.; Chilov, G. G.; Lipkin, A. V. Novel fragment-like inhibitors of EphA2 obtained by experimental screening and modelling. Mendeleev Commun. 2010, 20, 263-265.

39. Zuccotto, F.; Ardini, E.; Casale, E.; Angiolini, M. Through the "gatekeeper door": exploiting the active kinase conformation. J. Med. Chem. 2010, 53, 2681-2694.

40. Chang, Q.; Jorgensen, C.; Pawson, T.; Hedley, D. W. Effects of dasatinib on EphA2 receptor tyrosine kinase activity and downstream signalling in pancreatic cancer. Br. J. Cancer 2008, 99, 10741082.

41. Karaman, M. W.; Herrgard, S.; Treiber, D. K.; Gallant, P.; Atteridge, C. E.; Campbell, B. T.; Chan, K. W.; Ciceri, P.; Davis, M. I.; Edeen, P. T.; Faraoni, R.; Floyd, M.; Hunt, J. P.; Lockhart, D. J.; Milanov, Z. V.; Morrison, M. J.; Pallares, G.; Patel, H. K.; Pritchard, S.; Wodicka, L. M.; Zarrinkar, P. P. A quantitative analysis of kinase inhibitor selectivity. Nat. Biotechnol. 2008, 26, 127-132.

42. Type XIII RTKs: Ephrin receptor family: EPH receptor B4. Last modified on 26/03/2013. Accessed on 12/10/2014. IUPHAR database (IUPHAR-DB), http://www.iuphardb.org/DATABASE/ObjectDisplayForward?objectId=1833.

43. Melnick, J. S.; Janes, J.; Kim, S.; Chang, J. Y.; Sipes, D. G.; Gunderson, D.; Jarnes, L.; Matzen, J. T.; Garcia, M. E.; Hood, T. L.; Beigi, R.; Xia, G.; Harig, R. A.; Asatryan, H.; Yan, S. F.; Zhou, Y. Y.; Gu, X. J.; Saadat, A.; Zhou, V.; King, F. J.; Shaw, C. M.; Su, A. I.; Downs, R.; Gray, N. S.; Schultz, P. G.; Warmuth, M.; Caldwell, J. S. An efficient rapid system for profiling the cellular activities of molecular libraries. Proc. Natl. Acad. Sci. U. S. A. 2006, 103, 3153-3158.

44. Gendreau, S. B.; Ventura, R.; Keast, P.; Laird, A. D.; Yakes, F. M.; Zhang, W. T.; Bentzien, F.; Cancilla, B.; Lutman, J.; Chu, F.; Jackman, L.; Shi, Y. C.; Yu, P. W.; Wang, J.; Aftab, D. T.; Jaeger, C. T.; Meyer, S. M.; De Costa, A.; Engell, K.; Chen, J.; Martini, J. F.; Joly, A. H. Inhibition of the T790M gatekeeper mutant of the epidermal growth factor receptor by EXEL-7647. Clin. Cancer. Res. 2007, 13, 3713-3723.

45. Caligiuri, M.; Molz, L.; Liu, Q.; Kaplan, F.; Xu, J. P.; Majeti, J. Z.; Ramos-Kelsey, R.; Murthi, K.; Lievens, S.; Tavernier, J.; Kley, N. MASPIT: Three-hybrid trap for quantitative proteome fingerprinting of small molecule-protein interactions in mammalian cells. Chem. Biol. 2006, 13, 711722.

46. Burkholder, T. P.; Clayton, J. R.; Rempala, M. E.; Henry, J. R.; Knobeloch, J. M.; Mendel, D.; McLean, J. A.; Hao, Y.; Barda, D. A.; Considine, E. L.; Uhlik, M. T.; Chen, Y. F.; Ma, L. D.; Bloem, L. J.; Akunda, J. K.; McCann, D. J.; Sanchez-Felix, M.; Clawson, D. K.; Lahn, M. M.; Starling, J. J. Discovery of LY2457546: a multi-targeted anti-angiogenic kinase inhibitor with a novel spectrum of activity and exquisite potency in the acute myelogenous leukemia-Flt-3-internal tandem duplication mutant human tumor xenograft model. Invest. New Drugs 2012, 30, 936-949.

47. Bain, J.; Plater, L.; Elliott, M.; Shpiro, N.; Hastie, C. J.; Mclauchlan, H.; Klevernic, I.; Arthur, J. S. C.; Alessi, D. R.; Cohen, P. The selectivity of protein kinase inhibitors: a further update. Biochem. J. 2007, 408, 297-315.

48. Sturz, A.; Bader, B.; Thierauch, K. H.; Glienke, J. EphB4 signaling is capable of mediating ephrinB2-induced inhibition of cell migration. Biochem. Biophys. Res. Commun. 2004, 313, 80-88.

49. Kolb, P.; Kipouros, C. B.; Huang, D. Z.; Caflisch, A. Structure-based tailoring of compound libraries for high-throughput screening: Discovery of novel EphB4 kinase inhibitors. ProteinsStructure Function and Bioinformatics 2008, 73, 11-18.

50. Zhao, H. T.; Dong, J.; Lafleur, K.; Nevado, C.; Caflisch, A. Discovery of a Novel Chemotype of Tyrosine Kinase Inhibitors by Fragment-Based Docking and Molecular Dynamics. ACS Med. Chem. Lett. 2012, 3, 834-838. 
51. Zhou, T.; Caflisch, A. High-Throughput Virtual Screening Using Quantum Mechanical Probes: Discovery of Selective Kinase Inhibitors. Chemmedchem 2010, 5, 1007-1014.

52. Dong, J.; Zhao, H.; Zhou, T.; Spiliotopoulos, D.; Rajendran, C.; Li, X.; Huang, D.; Caflisch, A. Structural Analysis of the Binding of Type I, I1/2, and II Inhibitors to Eph Tyrosine Kinases. ACS Med. Chem. Lett. 2014, Article ASAP, DOI: 10.1021/ml500355x.

53. Zhao, H. T.; Huang, D. Z.; Caflisch, A. Discovery of Tyrosine Kinase Inhibitors by Docking into an Inactive Kinase Conformation Generated by Molecular Dynamics. Chemmedchem 2012, 7 , 1983-1990.

54. Zhao, H.; Huang, D. Hydrogen bonding penalty upon ligand binding. PLoS One 2011, 6, e19923.

55. Lafleur, K.; Huang, D.; Zhou, T.; Caflisch, A.; Nevado, C. Structure-based optimization of potent and selective inhibitors of the tyrosine kinase erythropoietin producing human hepatocellular carcinoma receptor B4 (EphB4). J. Med. Chem. 2009, 52, 6433-6446.

56. Lafleur, K.; Dong, J.; Huang, D.; Caflisch, A.; Nevado, C. Optimization of inhibitors of the tyrosine kinase EphB4. 2. Cellular potency improvement and binding mode validation by X-ray crystallography. J. Med. Chem. 2013, 56, 84-96.

57. Unzue, A.; Dong, J.; Lafleur, K.; Zhao, H. T.; Frugier, E.; Caflisch, A.; Nevado, C. Pyrrolo[3,2-b]quinoxaline Derivatives as Types I-1/2 and II Eph Tyrosine Kinase Inhibitors: Structure-Based Design, Synthesis, and in Vivo Validation. J. Med. Chem. 2014, 57, 6834-6844.

58. Bamborough, P.; Angell, R. M.; Bhamra, I.; Brown, D.; Bull, J.; Christopher, J. A.; Cooper, A. W.; Fazal, L. H.; Giordano, I.; Hind, L.; Patel, V. K.; Ranshaw, L. E.; Sims, M. J.; Skone, P. A.; Smith, K. J.; Vickerstaff, E.; Washington, M. N-4-Pyrimidinyl-1H-indazol-4-amine inhibitors of Lck: indazoles as phenol isosteres with improved pharmacokinetics. Bioorg. Med. Chem. Lett. 2007, 17, 4363-4368.

59. Jeong, E. J.; Liu, X.; Jia, X. B.; Chen, J.; Hu, M. Coupling of conjugating enzymes and efflux transporters: Impact on bioavailability and drug interactions. Curr. Drug Metab. 2005, 6, 455-468.

60. Davis, M. I.; Hunt, J. P.; Herrgard, S.; Ciceri, P.; Wodicka, L. M.; Pallares, G.; Hocker, M.; Treiber, D. K.; Zarrinkar, P. P. Comprehensive analysis of kinase inhibitor selectivity. Nat. Biotechnol. 2011, 29, 1046-1051.

61. Adams, R. H. Vascular patterning by Eph receptor tyrosine kinases and ephrins. Semin. Cell Dev. Biol. 2002, 13, 55-60.

62. Wang, Y. D.; Nakayama, M.; Pitulescu, M. E.; Schmidt, T. S.; Bochenek, M. L.; Sakakibara, A.; Adams, S.; Davy, A.; Deutsch, U.; Luthi, U.; Barberis, A.; Benjamin, L. E.; Makinen, T.; Nobes, C. D.; Adams, R. H. Ephrin-B2 controls VEGF-induced angiogenesis and lymphangiogenesis. Nature 2010, 465, 483-U108.

63. Hughes, C. S.; Postovit, L. M.; Lajoie, G. A. Matrigel: A complex protein mixture required for optimal growth of cell culture. Proteomics 2010, 10, 1886-1890.

64. Sato, M.; Ogasawara, H.; Oi, K.; Kato, T. Synthesis of 1,3-Dioxin-4-One Derivatives. Chem. Pharm. Bull. (Tokyo) 1983, 31, 1896-1901.

65. Miriyala, B.; Williamson, J. S. An efficient and rapid synthesis of beta-carboxamide derivatives using 2,2-dimethyl-2H,4H-1,3-dioxin-4-ones by microwave irradiation. Tetrahedron Lett. 2003, 44, 7957-7959.

66. Bogdanowiczszwed, K.; Policht, A. The Reaction of Malononitrile with Enamines of Some Cyclic Beta-Keto Acid Anilides and Amidines. J. Prakt. Chem. 1984, 326, 721-728.

67. Fabian, M. A.; Biggs, W. H., 3rd; Treiber, D. K.; Atteridge, C. E.; Azimioara, M. D.; Benedetti, M. G.; Carter, T. A.; Ciceri, P.; Edeen, P. T.; Floyd, M.; Ford, J. M.; Galvin, M.; Gerlach, J. L.; Grotzfeld, R. M.; Herrgard, S.; Insko, D. E.; Insko, M. A.; Lai, A. G.; Lelias, J. M.; Mehta, S. A.; Milanov, Z. V.; Velasco, A. M.; Wodicka, L. M.; Patel, H. K.; Zarrinkar, P. P.; Lockhart, D. J. A small molecule-kinase interaction map for clinical kinase inhibitors. Nat. Biotechnol. 2005, 23, 329336.

68. Pratt, E. F.; Kereszte.Jc. Syntheses of Indolizino- and Dihydroindolizinoquinoxalines. J. Org. Chem. 1967, 32, 49-\&.

69. Obafemi, C. A.; Pfleiderer, W. Synthesis and some reactions of 3-chloro-2-(cyanomethylene)1,2-dihydroquinoxalines. Molecules 2004, 9, 223-231.

70. Otomasu, H.; Ohmiya, S.; Sekuguch.T; Takahash.H. Synthesis of Condensed Quinoxalines .2. A New Synthesis of Pyrrolo- 2,3-B!Quinoxalines. Chem. Pharm. Bull. (Tokyo) 1970, 18, 2065-\&. 
71. Niesen, F. H.; Berglund, H.; Vedadi, M. The use of differential scanning fluorimetry to detect ligand interactions that promote protein stability. Nat. Protoc. 2007, 2, 2212-2221.

72. Angell, R. M.; Angell, T. D.; Bamborough, P.; Brown, D.; Brown, M.; Buckton, J. B.; Cockerill, S. G.; Edwards, C. D.; Jones, K. L.; Longstaff, T.; Smee, P. A.; Smith, K. J.; Somers, D. O.; Walker, A. L.; Willson, M. Biphenyl amide p38 kinase inhibitors 2: Optimisation and SAR. Bioorg. Med. Chem. Lett. 2008, 18, 324-328.

73. Graham Robinett, R.; Freemerman, A. J.; Skinner, M. A.; Shewchuk, L.; Lackey, K. The discovery of substituted 4-(3-hydroxyanilino)-quinolines as potent RET kinase inhibitors. Bioorg. Med. Chem. Lett. 2007, 17, 5886-5893.

74. Hynes, J., Jr.; Dyckman, A. J.; Lin, S.; Wrobleski, S. T.; Wu, H.; Gillooly, K. M.; Kanner, S. B.; Lonial, H.; Loo, D.; McIntyre, K. W.; Pitt, S.; Shen, D. R.; Shuster, D. J.; Yang, X.; Zhang, R.; Behnia, K.; Zhang, H.; Marathe, P. H.; Doweyko, A. M.; Tokarski, J. S.; Sack, J. S.; Pokross, M.; Kiefer, S. E.; Newitt, J. A.; Barrish, J. C.; Dodd, J.; Schieven, G. L.; Leftheris, K. Design, synthesis, and anti-inflammatory properties of orally active 4-(phenylamino)-pyrrolo[2,1-f][1,2,4]triazine p38alpha mitogen-activated protein kinase inhibitors. J. Med. Chem. 2008, 51, 4-16.

75. Deak, H. L.; Newcomb, J. R.; Nunes, J. J.; Boucher, C.; Cheng, A. C.; DiMauro, E. F.; Epstein, L. F.; Gallant, P.; Hodous, B. L.; Huang, X.; Lee, J. H.; Patel, V. F.; Schneider, S.; Turci, S. M.; Zhu, X. N-(3-(phenylcarbamoyl)arylpyrimidine)-5-carboxamides as potent and selective inhibitors of Lck: structure, synthesis and SAR. Bioorg. Med. Chem. Lett. 2008, 18, 1172-1176.

76. Knight, Z. A.; Shokat, K. M. Features of selective kinase inhibitors. Chem. Biol. 2005, 12, 621-637.

77. Kornev, A. P.; Haste, N. M.; Taylor, S. S.; Ten Eyck, L. F. Surface comparison of active and inactive protein kinases identifies a conserved activation mechanism. Proc. Natl. Acad. Sci. U. S. A. 2006, 103, 17783-17788.

78. Liu, Y.; Gray, N. S. Rational design of inhibitors that bind to inactive kinase conformations. Nat. Chem. Biol. 2006, 2, 358-364.

79. Blanc, J.; Geney, R.; Menet, C. Type II kinase inhibitors: an opportunity in cancer for rational design. Anticancer Agents Med. Chem. 2013, 13, 731-747.

80. Bold, G.; Altmann, K. H.; Frei, J.; Lang, M.; Manley, P. W.; Traxler, P.; Wietfeld, B.; Bruggen, J.; Buchdunger, E.; Cozens, R.; Ferrari, S.; Furet, P.; Hofmann, F.; Martiny-Baron, G.; Mestan, J.; Rosel, J.; Sills, M.; Stover, D.; Acemoglu, F.; Boss, E.; Emmenegger, R.; Lasser, L.; Masso, E.; Roth, R.; Schlachter, C.; Vetterli, W. New anilinophthalazines as potent and orally well absorbed inhibitors of the VEGF receptor tyrosine kinases useful as antagonists of tumor-driven angiogenesis. J. Med. Chem. 2000, 43, 2310-2323.

81. Smith, R. A.; Barbosa, J.; Blum, C. L.; Bobko, M. A.; Caringal, Y. V.; Dally, R.; Johnson, J. S.; Katz, M. E.; Kennure, N.; Kingery-Wood, J.; Lee, W.; Lowinger, T. B.; Lyons, J.; Marsh, V.; Rogers, D. H.; Swartz, S.; Walling, T.; Wild, H. Discovery of heterocyclic ureas as a new class of raf kinase inhibitors: identification of a second generation lead by a combinatorial chemistry approach. Bioorg. Med. Chem. Lett. 2001, 11, 2775-2778.

82. Khire, U. R.; Bankston, D.; Barbosa, J.; Brittelli, D. R.; Caringal, Y.; Carlson, R.; Dumas, J.; Gane, T.; Heald, S. L.; Hibner, B.; Johnson, J. S.; Katz, M. E.; Kennure, N.; Kingery-Wood, J.; Lee, W.; Liu, X. G.; Lowinger, T. B.; McAlexander, I.; Monahan, M. K.; Natero, R.; Renick, J.; Riedl, B.; Rong, H.; Sibley, R. N.; Smith, R. A.; Wolanin, D. Omega-carboxypyridyl substituted ureas as Raf kinase inhibitors: SAR of the amide substituent. Bioorg. Med. Chem. Lett. 2004, 14, 783-786.

83. Albaugh, P.; Fan, Y.; Mi, Y.; Sun, F. X.; Adrian, F.; Li, N. X.; Jia, Y.; Sarkisova, Y.; Kreusch, A.; Hood, T.; Lu, M.; Liu, G. X.; Huang, S. L.; Liu, Z. S.; Loren, J.; Tuntland, T.; Karanewsky, D. S.; Seidel, H. M.; Molteni, V. Discovery of GNF-5837, a Selective TRK Inhibitor with Efficacy in Rodent Cancer Tumor Models. ACS Med. Chem. Lett. 2012, 3, 140-145.

84. Weisberg, E.; Manley, P. W.; Breitenstein, W.; Bruggen, J.; Cowan-Jacob, S. W.; Ray, A.; Huntly, B.; Fabbro, D.; Fendrich, G.; Hall-Meyers, E.; Kung, A. L.; Mestan, J.; Daley, G. Q.; Callahan, L.; Catley, L.; Cavazza, C.; Azam, M.; Neuberg, D.; Wright, R. D.; Gilliland, D. G.; Griffin, J. D. Characterization of AMN107, a selective inhibitor of native and mutant Bcr-Abl. Cancer Cell 2005, 7, 129-141.

85. Liu, C.; Lin, J.; Wrobleski, S. T.; Lin, S.; Hynes, J.; Wu, H.; Dyckman, A. J.; Li, T.; Wityak, J.; Gillooly, K. M.; Pitt, S.; Shen, D. R.; Zhang, R. F.; McIntyre, K. W.; Salter-Cid, L.; Shuster, D. J.; Zhang, H.; Marathe, P. H.; Doweyko, A. M.; Sack, J. S.; Kiefer, S. E.; Kish, K. F.; Newitt, J. A.; 
McKinnon, M.; Dodd, J. H.; Barrish, J. C.; Schieven, G. L.; Leftheris, K. Discovery of 4-(5(cyclopropylcarbamoyl)-2-methylphenylamino)-5-methyl-N-propylpyrrolo[1,2-f][ 1,2,4]triazine-6carboxamide (BMS-582949), a clinical p38alpha MAP kinase inhibitor for the treatment of inflammatory diseases. J. Med. Chem. 2010, 53, 6629-6639.

86. Hynes, J., Jr.; Wu, H.; Pitt, S.; Shen, D. R.; Zhang, R.; Schieven, G. L.; Gillooly, K. M.; Shuster, D. J.; Taylor, T. L.; Yang, X.; McIntyre, K. W.; McKinnon, M.; Zhang, H.; Marathe, P. H.; Doweyko, A. M.; Kish, K.; Kiefer, S. E.; Sack, J. S.; Newitt, J. A.; Barrish, J. C.; Dodd, J.; Leftheris, K. The discovery of (R)-2-(sec-butylamino)-N-(2-methyl-5-(methylcarbamoyl)phenyl) thiazole-5carboxamide (BMS-640994)-A potent and efficacious p38alpha MAP kinase inhibitor. Bioorg. Med. Chem. Lett. 2008, 18, 1762-1767.

87. Wrobleski, S. T.; Lin, S.; Dhar, T. G.; Dyckman, A. J.; Li, T.; Pitt, S.; Zhang, R.; Fan, Y.; Doweyko, A. M.; Tokarski, J. S.; Kish, K. F.; Kiefer, S. E.; Sack, J. S.; Newitt, J. A.; Witmer, M. R.; McKinnon, M.; Barrish, J. C.; Dodd, J. H.; Schieven, G. L.; Leftheris, K. The identification of novel p38alpha isoform selective kinase inhibitors having an unprecedented p38alpha binding mode. Bioorg. Med. Chem. Lett. 2013, 23, 4120-4126.

88. Kufareva, I.; Abagyan, R. Type-II kinase inhibitor docking, screening, and profiling using modified structures of active kinase states. J. Med. Chem. 2008, 51, 7921-7932.

89. Pargellis, C.; Tong, L.; Churchill, L.; Cirillo, P. F.; Gilmore, T.; Graham, A. G.; Grob, P. M.; Hickey, E. R.; Moss, N.; Pav, S.; Regan, J. Inhibition of p38 MAP kinase by utilizing a novel allosteric binding site. Nat. Struct. Biol. 2002, 9, 268-272.

90. Copeland, R. A.; Pompliano, D. L.; Meek, T. D. Drug-target residence time and its implications for lead optimization. Nat. Rev. Drug Discov. 2006, 5, 730-739.

91. Kitagawa, D.; Gouda, M.; Kirii, Y. Quick evaluation of kinase inhibitors by surface plasmon resonance using single-site specifically biotinylated kinases. J. Biomol. Screen. 2014, 19, 453-461.

92. Wood, E. R.; Truesdale, A. T.; McDonald, O. B.; Yuan, D.; Hassell, A.; Dickerson, S. H.; Ellis, B.; Pennisi, C.; Horne, E.; Lackey, K.; Alligood, K. J.; Rusnak, D. W.; Gilmer, T. M.; Shewchuk, L. A unique structure for epidermal growth factor receptor bound to GW572016 (Lapatinib): relationships among protein conformation, inhibitor off-rate, and receptor activity in tumor cells. Cancer Res. 2004, 64, 6652-6659.

93. Paul W. Manley, S. W. C.-J., Gabriele Fendrich, Wolfgang Jahnke and Doriano Fabbro. Nilotinib, in Comparison to Both Dasatinib and Imatinib, Possesses a Greatly Prolonged Residence Time When Bound to the BCR-ABL Kinase SH1 Domain. In 53rd ASH Annual Meeting and Exposition, San Diego, USA, 2011.

94. Korff, T.; Augustin, H. G. Tensional forces in fibrillar extracellular matrices control directional capillary sprouting. J. Cell Sci. 1999, 112 ( Pt 19), 3249-3258.

95. Mgbonyebi, O. P.; Russo, J.; Russo, I. H. Roscovitine induces cell death and morphological changes indicative of apoptosis in MDA-MB-231 breast cancer cells. Cancer Res. 1999, 59, 1903 1910.

96. Huang, D. Z.; Caflisch, A. Library screening by fragment-based docking. J. Mol. Recognit. 2010, 23, 183-193.

97. Zhao, H.; Caflisch, A. Molecular dynamics in drug design. Eur. J. Med. Chem. 2014, http://dx.doi.org/10.1016/j.ejmech.2014.08.004. 
In Silico $\Longrightarrow$ Med Chem $\Longrightarrow$ In vitro $\Longrightarrow$ In vivo

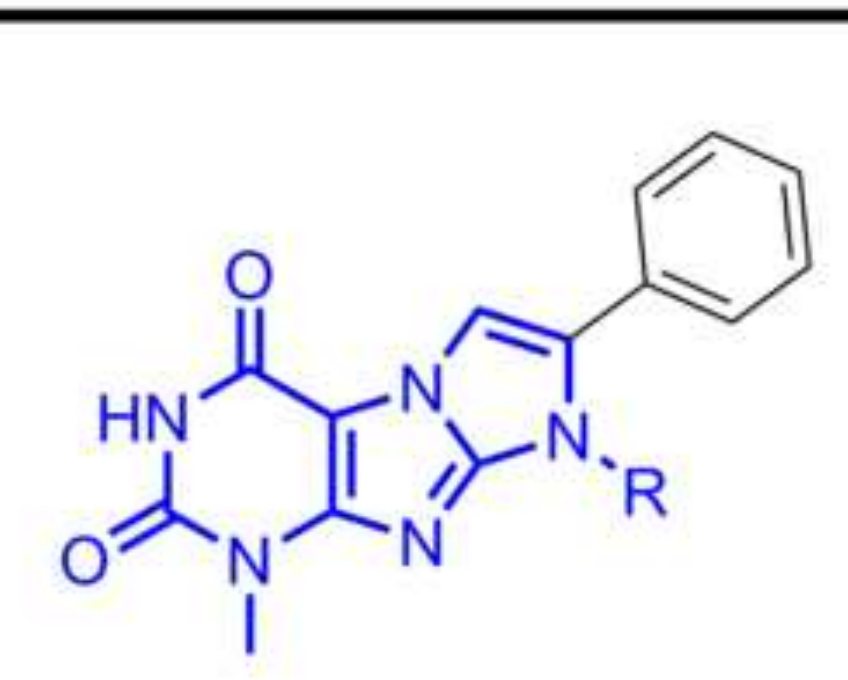

Xan

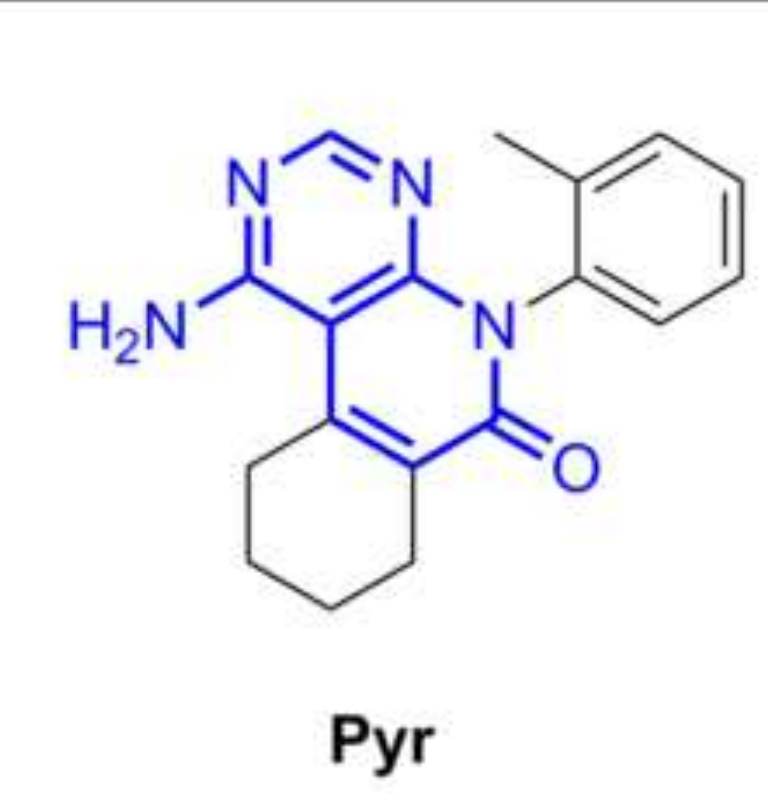

Pyr

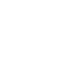

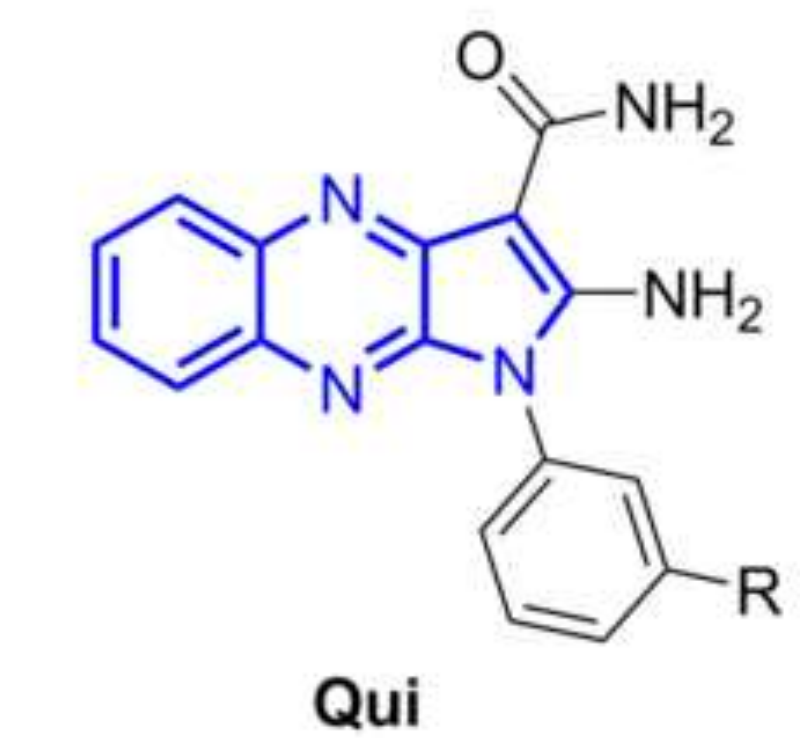

Qui 